\title{
Does the "Bund" dominate price discovery in Euro bond futures? Examining information shares
}

\author{
Christoph Fricke and Lukas Menkhoff
}

\begin{abstract}
This paper examines the relative information shares of the Bund, i.e. the ten-year Euro bond future contract on German sovereign debt, versus two futures with shorter maturity. We find that the Bund is most important but does not dominate price discovery. The other contracts also have relevant - and at many days even higher - information shares. In examining determinants of information shares, we add order flow measures to market state variables and macroeconomic news. More order flow in a contract consistently increases this contract's information share.
\end{abstract}

JEL-Classification: G 14 (information efficiency), G 13 (futures pricing), C 32 (time-series) Keywords: $\quad$ Bond futures, information shares, price discovery, order flow, macroeconomic news

May 19, 2010

We thank participants at the Money Macro and Finance Conference 2009, the Annual Meeting of the German Economic Association 2009 and the Warwick Business School Conference on High Frequency Econometrics 2009, in particular Torben G. Andersen, Francis Breedon, Stefan Frey, Joachim Grammig, Larry Harris, Erik Theissen and an anonymous referee for their valuable comments on earlier versions. We gratefully acknowledge data provided by Jan C. Rülke and financial support by the German Research Foundation (Deutsche Forschungsgemeinschaft DFG).

Christoph Fricke, Lukas Menkhoff; Leibniz Universität Hannover, Department of Economics, Königsworther Platz 1, D-30167 Hannover, Germany; fricke@gif.uni-hannover.de, menkhoff@gif.uni-hannover.de; tel.: +49-511-762-4552, fax: +49-511-762-4796. 


\section{Does the "Bund" dominate price discovery in Euro bond futures?}

\section{Examining information shares}

\section{Introduction}

The so-called "Bund" future contract is often regarded as the single most important asset in the Euro bond markets. The Bund is a standardized contract on German sovereign bonds with ten-year maturity. Due to its benchmark status the trading of this contract is expected to reflect the flow of news into this market more accurately than other assets. According to this view, the Bund would dominate price discovery in the Euro bond markets, i.e. the formation of interest rates. However, price discovery can occur over the whole yield curve and, for example, some news may be more important at shorter interest rates than ten years. Therefore, we examine the relative weight of the Bund future in price discovery versus two other liquid Euro bond future contracts. We find that the Bund is important indeed, but that it is not dominating at all.

The Bund future derives its benchmark status for European bond markets mainly from three facts (see Menkveld et al., 2004). First, Germany is the largest economy in the Euro area and its federal debt has the lowest risk spread. Second, future markets seem to be often more important than spot markets in price discovery, in particular if they are more liquid as it is the case here (see Covrig et al., 2004, for equities, Mizrach and Neely, 2008, for bonds). Third, among future contracts on German sovereign debt the Bund has about twice the trading volume than contracts on shorter maturities. Overall, there are good reasons to assume a leading role for the Bund in the process of discovering the interest rate level. There is indeed empirical evidence that German debt has a dominating role in the Euro area and we know that the Bund future dominates the ten-year bond (Upper and Werner, 2007, Schlusche, 2009). How- 
ever, we do not know of an empirical examination of the relative importance of the Bund in comparison to other Euro bond future contracts.

This examination has a natural motivation: we know that future contracts tend to be more important than the underlying bonds for price discovery, so, if there are several similar contracts as in our case, is any of them dominating? There is also a theoretical motivation for this research question as the expectation theory of the term structure suggests that changes in the short-term contract may roll-over to longer-term durations which Hall et al. (1992) test in a cointegration framework. Finally, Brandt and Kavajecz (2004) find a high importance of medium-term - 5 years - bonds as these best reflect average duration in bond portfolios and are thus most convenient for adjustment purposes in practice. Overall, there are good reasons to examine the Bund's dominance in price discovery.

Our research addresses exactly this issue: which contract (which market) is relatively most important in incorporating permanent price changes first, i.e. which contract is relatively most important in price discovery. We apply a standard econometric approach, i.e. the identification of "information shares". In detail, we use three related econometric techniques, i.e. information shares (Hasbrouck, 1995), modified information shares (Lien and Shresta, 2009) and HMW-information shares (Harris et al, 2002). ${ }^{1}$ This vector error correction approach aims for identifying the relative importance of certain time series to a common development. By applying it to financial markets one can analyze, for example, the relative contribution of single stock return histories to stock market development, the relative contribution of two markets or the relative contribution of two trading instruments. In our case, we are - to the best of our knowledge - the first to analyze the relative contribution of three bond future con-

\footnotetext{
${ }^{1}$ Harris et al. (2002) are the first to apply the technique of Gonzalo and Granger (1995) to financial markets. Therefore, Mizrach and Neely (2008) name this the "Harris-McInish-Wood information share"-approach, in short: HMW-approach.
} 
tracts to bond price development in one market. In particular, we examine the relative information shares of the Bund in comparison to the contracts with two- and five-year maturity.

As a second contribution, we examine possible determinants of information shares in order to better understand where or when price discovery takes place. These determinants come from three directions: first, we consider market state-related variables (see Mizrach and Neely, 2008), such as trading volume, volatility and spread, second, we take up the insight that macroeconomic news influence markets which has been modeled in the literature in various ways (Fleming and Remolona, 1999, Balduzzi et al., 2001, Andersen et al., 2007). Third, and according to our knowledge new to the literature on information shares, we consider order flow which is important for incorporation of information in bond markets too (e.g. Brandt and Kavajecz, 2004, Pasquariello and Vega, 2007).

We find indeed that the Bund has the largest information share and thus seems to be most important in price discovery of the interest rate level. Interestingly, however, despite its benchmark status, the Bund does not really dominate price discovery. Instead, all three considered contracts have considerable information shares and seem thus to be relevant. We gain further insight in the special roles of the single contracts by analyzing determinants of information shares. We see that market state-related variables are important determinants of information shares and that the effects behave quite consistently across all three future contracts. By contrast, macroeconomic news has relatively small and diverse effects. U.S. news seem mainly to be incorporated at the Bund, i.e. at the longer end of the yield curve, whereas press conferences of the European Central Bank have effects more on the Schatz, i.e. on the shorter end of the yield curve. Finally, we confirm from our perspective that order flow is a relevant medium of information incorporation. The relative contribution of unexpected order flow is generally less important but turns significant at non-announcement days, as found by Pasqua- 
riello and Vega (2007). Medium-sized trades as an indicator about the existence of "stealth trading" are quite insignificant in our sample (Barclay and Warner, 1993, Chakravarty, 2001).

This research fits into various lines of earlier work on price discovery in bond markets and extends earlier findings, first, by focusing on the European bond futures market, and second, by including order flow as determinant of information shares. For the U.S. market, Fleming and Remolona (1997) find the importance of news, a direction extended by Green (2004). Brandt et al. (2007) consider future markets and reveal the impact from order flow on prices. Mizrach and Neely (2008) are closest to our work as they also apply the information share-approach, although comparing for the U.S. the information shares of spot and future markets. There is less research on European markets. Upper and Werner (2007) are relatively closest to us in this respect as they also apply the information share-approach, however, to the German ten-year maturity only and without considering any determinants. Dunne et al. (2007) question the benchmark status of German sovereign debt, although without covering the most liquid future contracts in their analysis and Andersson et al. (2009) strictly focus on volatilityeffects due to macroeconomic announcements.

The paper is organized in the following steps: Section 2 describes the data and Section 3 outlines the econometric approach. Section 4 provides information shares and Section 5 examines its determinants, thus supporting an economic interpretation. Section 6 provides some robustness exercises and Section 7 concludes.

\section{Data}

The study is based on high frequency data of trading in the three most liquid Euro bond future contracts between 2004 and 2007. In addition, we use macroeconomic news as well as order flows for our analyses. 
The data on German government bond futures' trading ranges from 01.06.2004 to 07.06.2007. The three considered contracts are - with increasing maturity - the two-year maturity "Bundesschatzanweisungen" (in short: "Schatz"), the five-year "Bundesobligationen" ("Bobl") and the ten-year "Bundesanleihen" ("Bund"). These three contracts are the most liquid futures in the Euro area and they are all AAA-rated (S\&P). The underlyings are the maturity-related bonds each with a face value of 100.000 EUR and a yearly coupon payment of six per cent.

To concentrate our analyses to the most liquid contracts we make use of the 'auto roll' procedure, briefly described e.g. by Andersson et al. (2009). Contracts' trading is compared on a daily basis and the one with the highest volume is included into the data set. With this in hand and combined with the findings of Brandt and Kavajecz (2004) and Pasquariello and Vega (2007) who postulate that liquidity is related to the time to maturity, we focus our attention on 'on-the-run' contracts which dominate the price process (see Brandt and Kavajecz, 2004).

Our data are recorded at EUREX which is the only supplier of an electronic trading platform for fixed income futures in Germany and offers regular trading hours from 8:00 a.m. up to 6:00 p.m. till 20.11.2005 and up to 10:00 p.m. afterwards. The collected raw data provide the exact timestamp, last bid, ask and transaction price as well as its quantity. This gives us the possibility to construct trade related variables. Buy and sell identifications take place via the direct comparison of the transaction price and the quoted bid and ask. If the trade hits or understates the bid price, the order is classified as a sell and vice versa. In order to bring this information into a final data set which gives the opportunity of a comparison at the highest possible frequency we assign each contract for each second during the trading day an average possible trading price, represented by the midquote. This virtual price is computed as 
the half of summing up the bid and ask price. As we cannot observe a chainsaw pattern in our time series, as reported by Brandt et al. (2007), we do not need to control or to correct for this effect.

$\underline{\text { Table } 1}$ summarizes the major characteristics of our sample. Consistent with the U.S. Treasury market most of the trading per day is concentrated in the longer-term contract, i.e. the ten-year future (see Brandt et al., 2007). With 16,290 transactions per day on average and a total turnover of 959,056 contracts, it almost surpasses the two-year and the five-year contract by a factor of two and nurtures the view that the Bund future might be seen as the benchmark in the European bond market (Dunne et al., 2007).

Releases of macroeconomic news induce strong movements in the U.S. bond as well as in the German Bund future market (Fleming and Remolona, 1999, Andersen et al., 2007, Andersson et al., 2009). Thus it is necessary to analyze their impact in our sample, too. We use the International Money Market Survey (MMS) and Bloomberg to collect median forecasts and realizations of the relevant macroeconomic fundamentals. In determining our data set of U.S., Euro Area and German specific news, our selection is strongly influenced by Fleming and Remolona (1999). We consider their five most influential U.S. macroeconomic news (on the five-year on-the-run GovPX bond) and select their European and German equivalents, too. In detail, we take the unemployment statistics, producer and consumer price indexes, GDP and retail sales releases. We enrich the data set by adding further marketrelevant announcements, i.e. the U.S. nonfarm payroll employment (see Hautsch and Hess, 2007, or Andersen et al., 2007), the German industrial production and the German IFO industry survey of business climate (Ahn et al., 2002). Andersson et al. (2009) report leakages regarding the official release dates of the German unemployment rate, so that we use their correction of dates for this variable. 
Finally, given a high impact of the federal fund target rate (Fleming and Remolona, 1999), we include days with FOMC (Federal Open Market Committee of the U.S. central bank) meetings or ECB (European Central Bank) press conferences. As the FOMC's policy decisions are published outside the official trading hours the corresponding dummy variable is set to one for the next trading day.

Shorter-term price discovery regarding macroeconomic data refers mainly to its surprise component and less to the announcement as such. Thus, we define the news content of announcement i, $S_{i}$, as the difference between the realization $A_{i}$ and the median forecast $E_{i}$. For our purpose it does not make a difference whether the realization is larger or smaller than the median forecast. So we take the absolute difference of news as our measure (see also Chen and Gau, 2010). As the news content can differ across the announcements, we compute standardized news surprises for announcement $\mathrm{i}$ at day $\mathrm{t}$ by dividing the news content by its standard deviation $\sigma_{i}$,

$$
S_{i, t}=\frac{\left|A_{i, t}-E_{i, t}\right|}{\sigma_{i}}
$$

The last kind of data which is used in the empirical work is various measures of order flow. Order flow is a measure of signed transactions and can easily be constructed from the available data on futures trading.

\section{The econometric approach}

\subsection{Price discovery metrics}

Price discovery metrics are a standardized measure of price discovery for cointegrated time series in multiple markets or assets. We apply three standard approaches, i.e. the Hasbrouck (1995), the Lien and Shrestha (2009) and the Harris et al. (2002) approach. 
The efficient price process can be worked out by an error-correction model with the following representation (see Engle and Granger, 1987) ${ }^{2}$ :

$$
\Delta p_{t}=\alpha k_{t-1}+\sum_{i=1}^{s} \Gamma_{i} \Delta p_{t-i}+\varepsilon_{t}
$$

$\Delta p_{t}$ defines the price changes in period t, $\Gamma_{i}$ the corresponding coefficient matrix and $\alpha$ the error correction vector. $z_{t-1}$ captures the error-correction terms between the markets:

$$
z_{t-1}=\beta^{\prime} p_{t-1}
$$

with $\beta$ as the cointegration vector.

Expressing the price process in a vector moving average (VMA) implies that current price changes depend on price innovations $e_{t}{ }^{\prime}=\left[e_{1 t}, e_{2 t}, e_{3 t}\right]$ :

$$
\Delta p_{t}=\Psi(L) e_{t}=e_{t}+\Gamma_{1} e_{t-1}+\ldots+\Gamma_{s} e_{t-s}
$$

where $\Psi$ is a polynomial in the lag operator. The integrated form defines the current price as

$$
p_{t}=\Psi(1) \sum_{i=1}^{t} e_{i}+\Psi^{*}(L) e_{t}
$$

with $\Psi(1)$ as the sum of the moving average coefficients, defining the long-run impact of the disturbance terms. Johansen (1991) shows that $\Psi(1)$ depends on the orthogonal of the error correction terms, $\alpha_{\perp}$ and $\beta_{\perp}{ }^{3}$, and a scalar $\pi$,

$$
\Psi(1)=\alpha_{\perp} \pi \beta_{\perp}=\pi\left[\begin{array}{ccc}
\gamma_{1} & \cdots & \gamma_{N} \\
\vdots & \ddots & \vdots \\
\gamma_{1} & \cdots & \gamma_{N}
\end{array}\right]
$$

With $\gamma$ as the common row vector in (6) the permanent price change due to innovations is $\gamma^{\prime} e_{t}$. Up to this point the three measures are equal. ${ }^{4}$

\footnotetext{
${ }^{2}$ Detailed discussions about the efficient price process offer Hasbrouck (1991a) and Hasbrouck (2007).

${ }^{3}$ The orthogonal fulfils the following condition: $\alpha_{\perp}{ }^{\prime} \alpha=0, \beta_{\perp}{ }^{\prime} \beta=0$.
} 
Baillie et al. (2002) argue that in the case of low correlation between the error terms the Hasbrouck (1995) information share might be a more sensible metric than the HMW approach. As these conditions apply to our case we prefer the Hasbrouck metric for our analysis. To be on the safe side, however, we consistently also calculate and document the modified information share approach (Lien and Shrestha, 2009) and the HMW approach (see Lehmann, 2002). They are shortly introduced in the following.

\subsection{Information share approaches}

The Hasbrouck information share refers to the variance contribution of an asset to the efficient price variance $\operatorname{var}\left(\gamma^{\prime} e_{t}\right)$.If the error terms are uncorrelated, the variance-covariance matrix of the error terms, $\Omega$, is diagonal. In this case, the role of a price leader can be directly derived by weighting each variance term with its long-run impact factor. However, practical applications reveal an existing negative correlation with a higher sampling frequency (see Hasbrouck, 1995, and Theissen, 2002). Although we follow Hasbrouck's (1995) suggestion and set the studied time interval as fine as possible, we are not able to totally eliminate the covariance between both error terms. Consequently, we conduct a Choleski decomposition of $\Omega$ to derive a lower triangular matrix $\mathrm{M}$. The information share of contract $\mathrm{i}$ is defined as,

$$
I S_{i}=\frac{\left([\mathcal{M}]_{i}\right)^{2}}{\gamma \Omega \gamma^{\prime}}
$$

\footnotetext{
${ }^{4}$ Consequently, de Jong (2002) demonstrates the strong econometric relation between the Hasbrouckand HMW-information shares. These two measures also show a high correlation in practice (see Theissen, 2002). However, Hasbrouck (2002) discusses examples in which both approaches report different results. Yan and Zivot (2010) explain these disparities by different responses to temporary price movements. Lien and Shrestha (2009) introduce the modified information share which partly outperforms the previous discussed approaches.
} 
with $[\not M M]_{i}$ as the $\mathrm{i}$-th element of the row of the matrix $\not M$. We rotate the ordering of the contracts in $\Omega$ to derive upper and lower bounds (see Hasbrouck, 1995). As the difference between both bounds is not too large, we consider the averages for our analysis (see Table 4).

The purpose of the modified information share is to derive a unique measure which is independent of the ordering in the variance-covariance matrix. Therefore, Lien and Shrestha (2009) suggest using a eigenvalue-eigenvector decomposition of the correlation matrix of the error terms, $\Phi$. Define $\Lambda$ as a diagonal matrix with the eigenvalues of the error terms' correlation matrix as the diagonal elements and $\mathrm{G}$ contains the corresponding eigenvectors in the column vectors. Let $\mathrm{V}$ represent a diagonal matrix with the standard deviation of the price innovations, such that $V=\operatorname{diag}\left(\sqrt{\Omega_{11}}, \sqrt{\Omega_{22}}, \sqrt{\Omega_{33}}\right)$. Then (8) defines a unique measure:

$$
M I S_{i}=\frac{\gamma_{i}^{* 2}}{\gamma \Omega \gamma^{T}}
$$

where $\gamma^{*}=\gamma\left[G \Lambda^{-1 / 2} G^{T} V^{-1}\right]$.

The HMW approach uses the permanent/transitory decomposition of Gonzalo and Granger (1995) to calculate the common component of the price innovations. In a price series framework prices are decomposed into a permanent, $f_{t}$, and a temporary, $\tilde{p}_{t}$, component,

$$
p_{t}=A f_{t}+\tilde{p}_{t}
$$

where $A$ is a factor loading matrix. The orthogonal of the common row vector in (6), $\gamma_{\perp}$, represents the long-run impact (Gonzalo and Granger, 1995). ${ }^{5}$ Considering $\gamma_{\perp}$ will yield to an unbounded measure. In order to avoid interpreting negative information shares we consider

\footnotetext{
${ }^{5}$ Baillie et al. (2002) demonstrate the applicability of the Gonzalo-Granger approach to financial data.
} 
the absolute magnitudes of the factor weights ${ }^{6}$ (see Cabrera et al., 2009 and Tswei and Lai, 2009):

$$
I S^{G G^{\prime}}=a b s\left(\gamma_{\perp}^{\prime}\right)\left(a b s\left(\gamma_{\perp}^{\prime}\right)\right)^{-1}
$$

where $\iota$ is a $(3 \times 1)$ vector of ones.

\section{Information shares of the future contracts}

This section develops our first main result, i.e. showing that the Bund is relatively most important for price discovery although the two other future contracts also attract major information shares.

\subsection{Preparatory analysis}

As the information share-approach is based on a VECM method, the appropriateness of time series has to be tested first. The purpose of this section is thus to test for two basic requirements, i.e. non-stationarity of each contract's time-series and the cointegration of all three futures' time-series. First, analyzing the non-stationarity condition of the time series, we conduct the augmented Dickey-Fuller test on a daily basis. Here and in further analyses the applied lag length is estimated by relying on the Bayesian information criterion. Table 2 reports the results. The lag-length differs over the three contracts, ranging from 4 at the tenyear's future contract up to 7 in the two-year's one. Over the whole sample, we cannot reject the unit root characteristic for any of the three time series.

Second, we apply the Johansen likelihood ratio (LR) test for the whole system to receive its rank (see Johansen, 1988). However, and consistent with Mizrach and Neely (2008), we are not able to reject the null of zero cointegration at all days. Because our intention is to

\footnotetext{
${ }^{6}$ The exclusion of the days with negative information shares, as suggested by Campbell and Hendry (2007) does change our results.
} 
receive unanimously identified information shares we drop the days where we observe no cointegration; their inclusion would produce misleading results and distort the information shares. In 405 cases we do not reject the null hypothesis of a rank of $2(r=2)$. For these days the optimal lag length is on average 19. Table 2 Panel A shows the average trace- and eigenvalue test statistics which reject the null hypothesis of the existence of either none or one cointegrating vector.

For robustness and in order to expand the examination, we additionally analyze the cointegration relation of the two- and five-year contract, each compared to the ten-year's one. ${ }^{7}$ Panel B reports the test statistics for the binary cases. Here we get a sample of 534 observations for the two-year contract and 578 observations for the five-year one on which we are able to apply the Hasbrouck information share approach.

We are aware that this procedure might possibly exclude important days at which the yield curve, especially the slope, changes. For this purpose we test whether changes of the slope, trading volume or volatility differ on days with and without cointegration (Table 3 ). We reject the $\mathrm{H}_{\mathrm{o}}$ of equal means for percentage slope changes in the case of either the two- or the five-year contract. Additionally, results reveal a lower trading volume in all contracts at non-cointegration days. Therefore, the significant higher volatility of the ten-year contract at days without cointegration is a result of the lower liquidity in market overall. In sum, these tests do not indicate any selection bias of our sample.

\subsection{Information shares}

\footnotetext{
${ }^{7}$ This specification focuses on the economic most relevant relations as the Bund future might be seen as a benchmark in the price discovery process.
} 
This section reports information shares of the Bund, Bobl and Schatz futures. Although we find a high and dominating share of the ten-year future contract, the shorter-maturity contracts contribute in sum about $40 \%$ to price discovery.

Yearly averages of daily information shares for the two-, five and ten-year contracts are reported in Table 4. Although there are some fluctuations of the estimated values, the ten-year contract is clearly the relatively most important contract for price discovery with a share of roughly $60 \%$ - i.e. there remains about $40 \%$ for the two other contracts. This $40 \%$ breaks up into $25 \%$ for the five-year contract and $15 \%$ for the shortest maturity. The Bund's importance becomes also evident in daily data, because its information share is above $50 \%$ on more than six out of ten days. The Bobl dominates price discovery at $10 \%$ of days and the two-year future exceeds the $50 \%$ level only at $6 \%$ of days.

In order to show permanency of the Bund's relative importance over time Figure 1 reports the daily information shares. In particular the inferior role of the five-year Bobl may be somewhat surprising compared to related findings in the literature. Brandt and Kavajecz (2004) attribute the highest price impact to the five-year Treasury order flow and refer to the duration of the majority of fixed income portfolios, which is close to five years. Considering the U.S. spot and future market, Brandt et al. (2007) point out that the five-year's order flow of both markets has the most important role in pricing fixed income assets. Our result seems to be different although also in Germany the duration of bond portfolios is closest to the fiveyear contract and liquidity is not particularly high in that future contract. We suggest two reasons for this. First, different from the other mentioned analyses we refer to the concept of information shares so that neither econometric approach nor the period of investigation are the same. Second, in the Euro bond future market the Bund is characterized by the highest trading volume whereas in the U.S. there is also a liquid thirty-year market segment which attracts 
some trading and price discovery; so, possibly the Bund has a relatively strong position in price discovery due to this institutional difference.

\section{Determinants of information shares}

This section presents the results of three groups of determinants which may help to explain information shares. Section 5.1 considers market state-related variables. Section 5.2 contains variables about macroeconomic variables and in Section 5.3 we introduce order flow by three new variables, i.e. (i) total order flow, (ii) unexpected order flow and (iii) medium-sized trades. Finally, in Section 5.4 the variables from the three earlier sections are considered together. Results extend our economic intuition of price discovery in the bond market.

\subsection{Determinants of information shares: market state variables}

The analysis of information shares has shown that they can vary considerably over time and that this instability may be related to variables indicating varying market states. Potentially relevant market states include spread, trading volume and volatility (see Fleming, 2003, Brandt et al., 2007). The analysis of market state variables has two motivations: first, one may learn from this analysis under which market conditions information is preferably compounded into prices. Second, one may think about market state variables as exogenous control variables which help to reveal the unconditional information shares of a certain market, such as the Bund.

Our analysis in the following is inspired by Mizrach and Neely (2008) who are the first to consequently consider the three above introduced market state variables in the Hasbrouck (1995) approach. Mizrach and Neely (2008) show that spread, traded contracts and volatility are able to explain price discovery shifts between the U.S. spot and future market. Thus, we 
take up these three market state variables. Moreover, in order to control for more technical (and less economical) effects of the time-to-delivery and the delivery day of future contracts and the delivery day of fixed income options, we also consider in all specifications such standard control variables. Thus we conduct the regression,

$$
\begin{aligned}
\ln \left(I S_{i, t} /\left(1-I S_{i, t}\right)\right)=c & +b_{1} T T D+b_{2} D D+b_{3} O D D \\
& +b_{4} \ln \left(S p r_{i, t}\right)+b_{5} \ln \left(V_{i, t}\right)+b_{6} \ln \left(R V_{i, t}\right)+\varepsilon_{i, t}
\end{aligned}
$$

with i representing contract's maturity and IS the maturity-specific daily information share.

$S p r, V$ and $R V$ represent the daily shares of spread, trading volume and realized variance which are the contract specific data divided by the sum over all three future contracts. Checking for any future market specific distortions we consider the time-to-delivery (TTD) and the delivery day of futures (DD) and their corresponding options (ODD), where the latter two are dummy variables with a value of one, if a new contract or option is issued. We use a logarithmic transformation of the information shares and microstructure variables to overcome any distributional problems related to limited depend variables (see Mizrach and Neely, 2008).

The expectations on coefficient signs - according to Mizrach and Neely (2008) - are that a relative higher spread of a future contract increases the price of incorporating noncommon knowledge and so hampers the tatonnement. In contrast, a higher share of trading volume indicates more information processing - or at least facilitates informed trading - and thus increases the information share. Finally, the impact from realized volatility may be ambiguous: this may be seen as an indicator of present noise traders in the market, so that more volatility decreases the information share, but it can be seen as sign of heterogeneously distribution information processing which would explain a positive sign. Although these results are confirmed for the spot-future-relation in the bond market (Mizrach and Neely, 2008) and for 
stocks and options (Chakravarty et al., 2004), they should not be seen as stylized facts. For example, Campbell and Hendry (2007) partly report different results for the Canadian and U.S. bond market. There, in some cases a higher share of trading volume harms the speed of price discovery. In other cases a relative increase of the spread or the volatility raises the information share. Overall, there is evidence that market state variables are important but their signs are less obvious ex ante.

Our estimated coefficients - shown in Table 5 for the three econometric approaches each - confirm the observation that market state variables are able to describe fluctuations in the information shares of bond future contracts. Overall, these variables are better in explaining shifts in information shares of the Bund and the Schatz than of the Bobl. A positive change of the trading volume from the $25^{\text {th }}$ to the $75^{\text {th }}$ percentile increases the information content of the ten- (five-/two-) year contract by $11.3 \%(3.1 \%, 2.7 \%){ }^{8}$ Interestingly, increases in spreads do not indicate less information processing in general because for the five-year contract a higher spread increases the information share; this particular role may be related to the use of the five-year contract as a hedging instrument for informed traders who increase information asymmetry and thus the spread (Brandt et al., 2007). Volatility reveals the expected negative signs, where the HMW approach provides most significant relations. This may be understood in the sense of Yan and Zivot (2010) who state that the HMW approach reacts more sensible to (noise traders or) temporary price impacts.

The future market specific variables also show reasonable signs. At either futures' (DD) or options' delivery day (ODD) informed traders prefer trading the more liquid Bund future which results in a higher information share of this contract. Consequently, the time-to-

\footnotetext{
${ }^{8}$ We base this calculation on the results of Table 5 and assume that the percentage spread and volatility remain at their means. The dummy variables of the delivery days of options and futures are set to zero. The time-to-maturity corresponds to its sample mean. The $25^{\text {th }} / 75^{\text {th }}$ percentile of the trading volume of the ten- (five-/two-) year contract are 47.5\%/52.8\% (24.0/27.3\%; 22.09\%/25.7\%).
} 
delivery (TTD) variable behaves in a complementary way. The adjusted $\mathrm{R}^{2} \mathrm{~s}$ do not exceed the 5\% level which is similar to the lowest value Mizrach and Neely (2008) observe in their study. This encourages us to exploit further determinants of information shares.

Overall, more favourable market states, i.e. more volume, lower spread and lower volatility, tentatively increase the information share of a certain contract. Exceptions indicate that informed traders may be willing to trade in certain instruments even under high spreads or high volatility.

\subsection{Determinants of information shares: macroeconomic news}

There is no doubt that macroeconomic news is an important element of the price discovery process in bond markets and should therefore be considered in an analysis of information shares. Again, as with market state variables, this consideration may provide interesting insights by itself and may also be regarded as a consideration of necessary control variables.

Among the first in this line of research in our field are Upper and Werner (2007) who show that two markets' contributions to the common trend may depend on incoming economic news. As an example they refer to the LTCM crisis (September $24^{\text {th }}$ to October $8^{\text {th }}$, 1998) during which the importance of the German spot compared to its future market tended to be zero. Mizrach and Neely (2008) generalize this hypothesis by reporting a negative impact of macroeconomic announcements on the importance of the spot market. Andersson et al. (2009) report significant price impacts of domestic, European and U.S. announcements for the German ten-year bond future. Furthermore, Andersen et al. (2007) detect strong but shortlived news-effects on the five-year contract in an international context. Given these results, we regress the information shares on the absolute values of the macroeconomic news, $S_{A, t}$, 
and additionally control for specific effects of future contracts, i.e. their time-to-delivery and delivery day as well on their options' delivery day ${ }^{9}$

$$
\ln \left(I S_{i, t} /\left(1-I S_{i, t}\right)\right)=c+b_{1} T T D+b_{2} D D+b_{3} O D D+S_{A, t}+\varepsilon_{i, t}
$$

Table 6a confirms the importance of macroeconomic news for the relation between different maturity bonds, here estimated via the Hasbrouck approach. We discuss findings in three steps: (1) we analyze results within countries, (2) we compare across countries and (3) we compare across econometric approaches (results of to the two other approaches are presented in separated tables).

(1) Starting the within country discussion with the U.S. news, their significance underlines their importance for estimating European yields (Andersen et al., 2007, Faust et al., 2007, and Ehrmann and Fratzscher, 2005). The importance of U.S. news stems from the financial and economic importance of the U.S. economy; Andersson et al. (2009) also suggest earlier U.S. release dates as a reason. The nonfarm payroll employment has on average the highest impact on the information shares, in line with findings of Andersen et al. (2007) and Andersen and Bollerslev (1998). Whereas this information is mainly incorporated through the two shorter-term contracts, all other significant effects induce information share shifts in favour of the ten-year future. With the exception of retail sales all signs of the macroeconomic announcements are in line with the findings of Goldberg and Leonhard (2003).

Turning to the Euro Area variables, we observe a significant impact of all macroeconomic news in the one or other way. In contrast to the U.S. results, coefficients' signs do not

\footnotetext{
${ }^{9}$ We also control for asymmetric news responses of the information shares by considering positive and negative news separately in our regressions. This method leads to a drop of explanatory power and does not change our interpretations (results are available on request). We see this as a confirmation of the existing literature which uses either dummy variables (Mizrach and Neely, 2008) or absolute news surprises (Chen and Gau, 2010) for explaining information shares.
} 
show any clear direction to one of the three contracts. The occurrence of ECB conferences heavily loads on the short end of the yield curve, indicating that the ECB mainly commands over the short-term end of the yield curve. This effect is underlined by the inflation-related CPI variable. Its early release date favours the CPI as a proxy for ECB decisions. The positive impact of the GDP and CPI variable on the shorter-maturity contracts is consistent with Goldberg and Leonhard (2003). Somewhat surprising is the large coefficient of GDP and retail sales on the five-year future.

Within the German news there is a pattern in that most news seem to affect the shortterm contract positively but the long-term contract negatively and with the medium-term contract in between. The single most important variable is the ifo business climate which is regarded as a reliable early indicator of future growth and price pressure. The next important variable is jobless claims, which has the opposite signs to the ifo variable. The signs of the GDP and the CPI variable are consistent with Goldberg and Leonhard (2003).

(2) Comparing the coefficients across countries, we see that generally the size of significant U.S. variables is larger than the sizes of Euro Area or German variables indicating the strong impact of U.S. news on the Euro bond futures (see Ahn et al., 2002, ChristieDavid et al., 2002). Next, we see that the U.S. influence is mainly channelled via the Bund whereas German news mainly affects the two-year contract. Regarding the significance of variables across countries, three variables stand out as they are important in each country: this is, first, jobless claims and nonfarm payroll employment in the U.S. respectively, second, consumer prices are highly significant everywhere, and, third, decision makers expectations, such as central bank meetings or important surveys in Germany, matter for price discovery. Unfortunately, the signs of variables across countries do not provide a fully consistent pattern. 
This indicates, as our work with various specifications demonstrates, that one should not emphasize the significance of single coefficients too much.

(3) In order to compare results across the three econometric approaches, we provide the additional results in Table $6 \mathrm{~b}$ for the modified information share-approach and in Table $6 \mathrm{c}$ for the HMW-approach. Taking the Hasbrouck approach as the benchmark, the modified information share-approach reproduces significant coefficients almost exactly as there is just one marginal exception (German industrial production at the five-year contract). The HMWapproach differs a bit more from the Hasbrouck-approach and produces twelve cases (out of 60 coefficients in total) where significance is gained or lost, although there is no single case where a significant variable would change sign. These effects might be linked to microstructure noise effects which more heavily influence the HMW-approach (see Yan and Zivot, 2010). Fortunately, these changes are almost random scattered across the table so that the above derived conclusions about pattern within and across countries still hold.

\subsection{Determinants of information shares: order flow}

This section investigates the role of order flow in shifting the share of price discovery, i.e. the information share, between the three future contracts. There are two motivations why order flow may be a relevant determinant in this analysis. First, order flow is a medium for incorporating non-common knowledge into prices (e.g. Killeen et al., 2006). In bonds' spot and future markets this measure plays an important role in explaining price dynamics (see Brandt and Kavajecz, 2004, Brandt et al., 2007 and Underwood, 2009). Second, Green (2004) documents the processing of news via an indirect channel, i.e. via order flow, which motivates us to distinguish between days with news and days without. ${ }^{10}$

\footnotetext{
${ }^{10}$ See Evans and Lyons (2008) for an exact distinction between the direct and indirect channel.
} 
In line with earlier studies on the possible impact of order flow on prices we proceed with the analysis in four steps, from general to specific, i.e. considering (A) total order flow, (B) unexpected order flow, (C) medium-sized order flow and then including market state variables (from Section 5.1). We note that these time-series are not significantly correlated with each other.

(A) Total order flow

Order flow is a measure of signed trades and thus indicates buying pressure (assuming that buys are coded positive). It is well documented that order flow is positively related to contemporaneous returns in many markets. This is often interpreted as an indication for order flow being the medium for incorporating information into prices. According to this reasoning one might expect that order flow will also impact information shares.

We test this in the simplest way by regressing relative order flow, i.e. between the Bund, Bobl and the Schatz, on their information shares. In order to do so we divide the absolute value of the maturity-specific, volume-weighted order flow by the sum over all three future contracts. Moreover, in order to distinguish the net trading effect on days with and without news, we create two dummy variables, each capturing one state. These dummies are multiplied with the order flow. Table 7 Panel A shows that the two- and ten-year contracts are indeed positive and statistically significant for days with news but also for days without news. Only the five-year contract does not show significant coefficients which may be due to the special purpose of the five-year contract as preferred hedging instrument. We see this preliminary result as a confirmation of the derived implications of Section 5.2 that the information flow is mainly located at the short- and long end of the yield curve. 


\section{(B) Unexpected order flow}

Going further, it has been argued that order flow may contain elements that are not related to information. One way to extract the truly informative part of order flow has been suggested by Pasquariello and Vega (2007). They document a linkage between unexpected order flow and information processing in the bond market which is pronounced at nonannouncement days and less relevant at announcement days. To extract the pure informative part from the order flow we follow Pasquariello and Vega (2007) and run a regression of the lagged returns and order flows on the current order flow and define the residuals $v(O F)$ as unexpected order flow ${ }^{11}$

$$
O F_{i, t}=\alpha_{i}+b(L) O F_{i, t}+c(L) R_{i, t}+v(O F)_{i, t}, \quad \mathrm{i}=2-, 5-\text { and } 10 \text { years }
$$

$\mathrm{OF}$ and $\mathrm{R}$ refer to the order flow respectively return in contract i, $b(L)$ and $c(L)$ are polynomials in the lag operator. Applying the Bandi and Russel (2006) algorithm to minimize the effects of microstructure noise reveals an optimal sampling frequency of five minutes for the two- and five-year contract and six minutes for the ten-year's one. The Bayesian information criterion suggests using a lag length of nine for the two shorter maturity contracts and 8 for the Bund future in (13). The residuals of this regression, $v(O F)$, reveal the amount of unexpected order flow in a trading interval and are summed up per day. ${ }^{12}$ This gives us a measure for informed order flow, possibly nurtured by customer order flow (Menkveld et al., 2007).

In the next step we reproduce the steps as described in (A) above. The two columns in

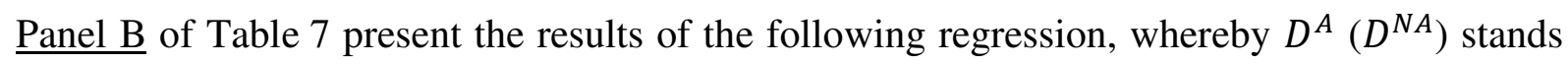
for a dummy variable, representing announcement (non-announcement) days:

\footnotetext{
${ }^{11}$ Hasbrouck (1991b) introduced this methodology for the estimation of the unanticipated component of a trade.

${ }^{12}$ For robustness we apply two specifications. First, we substitute the binary measured order flow for the volume-weighted order flow. Second, we choose a sampling frequency of 30 minutes. The appropriate lag-lengths are chosen to eliminate the serial correlation in the trading interval and are set such that a whole trading day is covered as we can see day-to-day dependencies in the returns. Our results remain stable and underline our conclusions.
} 


$$
\begin{aligned}
\ln \left(I S_{i, t} /\left(1-I S_{i, t}\right)\right)=c & +b_{1} T T D+b_{2} D D+b_{3} O D D \\
& +b_{4} \ln \left(\left|O F_{i, t}\right|\right) D^{N A}+b_{5} \ln \left(\left|O F_{i, t}\right|\right) D^{A} \\
& +b_{6} \ln \left(\left|U O F_{i, t}\right|\right) D^{N A}+b_{7} \ln \left(\left|U O F_{i, t}\right|\right) D^{A}+\varepsilon_{i, t}
\end{aligned}
$$

Two effects are directly observable. First, while we observe a positive impact of unexpected order flow on the information share of the Bund, total order flow loses its significant impact on information shares at non-announcement days. Second, with the exception of the Bund future traders pay less attention to unexpected order flow at announcement days. In general, we are able to confirm main findings of Pasquariello and Vega (2007) that the impact of both order flow measures is state-dependent.

(C) Medium-sized order flow

In a next step we further augment the regression by also considering medium-sized order flow. Medium-sized order flow is often found to be preferably used by informed traders according to the so-called stealth-trading hypothesis (Barclay and Werner, 1993). In order to reduce their price impact and so to lower their trading costs, informed investors split up large trades. If this applies here as well, then medium-sized trades have a larger price impact than small or large trades (evidence in Anand and Chakravarty, 2007, for options, Chakravarty, 2001, for equities, and in Menkhoff and Schmeling, 2010, for foreign exchange).

We compute contract i's daily share of medium-sized trades, $\mathrm{MID}_{\mathrm{i}}$, in three steps. First, we standardize all trades of a day. Next, we define the $20 \%$ and $80 \%$ critical trade sizes of each subsample. ${ }^{13}$ Finally, the amount of the maturity-specific trades between the borders is

\footnotetext{
${ }^{13}$ The choice of an upper and lower bound might change or results. Therefore, we test the robustness of our results in two ways. First, we set the thresholds to the $10 \%$ and $90 \%$ interval. Second, we adopt the methodology of Anand and Chakravarty (2007). They define trades with quantities between five
} 
divided by the sum over the three futures. The average shares of the two-, five- and ten-year contract are $14.7 \%, 25.7 \%$ and $59.6 \%$ which nearly corresponds to the unconditional information shares.

$$
\begin{aligned}
\ln \left(I S_{i, t} /\left(1-I S_{i, t}\right)\right)=c & +b_{1} T T D+b_{2} D D+b_{3} O D D \\
& +b_{4} \ln \left(\left|O F_{i, t}\right|\right) D^{N A}+b_{5} \ln \left(\left|O F_{i, t}\right|\right) D^{A} \\
& +b_{6} \ln \left(\left|U O F_{i, t}\right|\right) D^{N A}+b_{7} \ln \left(\left|U O F_{i, t}\right|\right) D^{A} \\
& +b_{6} \ln \left(\left|M I D_{i, t}\right|\right) D^{N A}+b_{7} \ln \left(\left|M I D_{i, t}\right|\right) D^{A}+\varepsilon_{i, t}
\end{aligned}
$$

$\underline{\text { Panel } \mathrm{C}}$ in Table 7 reports respective results which are, however, qualitatively unchanged to the earlier reported Panels A and B.

Without going into details, we cautiously conclude that stealth-trading may be not very relevant in the bond future market; at least not as important as in other markets.

(D) Including market states

Finally, $\underline{\text { Panel D }}$ adds the market state variables to the order flow variables in joint regressions. Reassuringly, the order flow variables which were significant keep significance (and signs). At non-announcement days the previously observed positive impact of mediumsized order flow of the two-year contract vanishes after the inclusion of spread, volume and volatility.

Comparing the results with Table 5 reveals a remarkable increase of the explanatory power. We conduct Wald Tests to evaluate the role each order flow variable plays for the information shares. Table 8 shows the results of subsequently including order flow, unexpectedand medium-sized order flow to the standard variables of Section 5.1. Both, the inclusion of order flow and unexpected order flow significantly improves our understanding of informaand 99 contracts as medium sized trades. This corresponds to a lower (upper) bound of $2.5 \%$ (40\%). However, both specifications do not change our results. 
tion shares of the shortest and longest maturity. Once again, this finding underlines the argumentation of Pasquariello and Vega (2007) that the importance of order flow depends on the existence of public signals.

Overall, we conclude that order flow is a useful determinant in explaining information shares, thus providing another form of evidence that order flow is a medium for incorporating private information.

\subsection{Determinants of information shares: market state, macroeconomic news and order flow}

In a final analysis, we consider all so far considered useful variables in a comprehensive approach. This provides some insight whether the variables found so far are possibly capturing common sources or whether they are orthogonal to each other. We find that only a few macroeconomic news change significance and want to remind that their overall explanatory power is very low anyway.

Formally, we test the following specification which can be seen as integrating variables from Section 5.1 to 5.3:

$$
\begin{aligned}
\ln \left(I S_{i, t} /\left(1-I S_{i, t}\right)\right)= & +b_{1} T T D+b_{2} D D+b_{3} O D D+S_{A, t} \\
& +b_{4} \ln \left(S p r_{i, t}\right)+b_{5} \ln \left(V_{i, t}\right)+b_{6} \ln \left(R V_{i, t}\right) \\
& +b_{4} \ln \left(\left|O F_{i, t}\right|\right)+b_{5} \ln \left(\left|O F_{i, t}\right|\right) D^{A} \\
& +b_{6} \ln \left(\left|U O F_{i, t}\right|\right)+b_{7} \ln \left(\left|U O F_{i, t}\right|\right) D^{A} \\
& +b_{6} \ln \left(\left|M I D_{i, t}\right|\right)+b_{7} \ln \left(\left|M I D_{i, t} M E D\right|\right) D^{A}+\varepsilon_{i, t}
\end{aligned}
$$

Results are given in Panels B of Tables 6a to 6c. Mainly, they confirm our previous results. The major deviation from the earlier presented partial regression is that there are a few 
changes in macroeconomic news, however, without changes that would suggest new interpretations. In particular, the order flow variables keep their significance and structure which indicates their contribution.

Overall, we do not see these minor modifications as a qualitative change in findings but rather as a confirmation of the overall message: market state variables and to a smaller extent order flow are the important determinants of information shares, whereas macroeconomic news is of less importance.

\section{Robustness}

In order to examine whether our findings are robust to modifications we aim for enlarging the number of days considered in our empirical analysis in two steps.

\subsection{Including further days in the analysis}

We test if the above derived results are an outcome of focussing exclusively on days with a cointegration of the three future contracts. For this reason, we now estimate the information shares only for the two- and five-year contract, each compared to the ten-year's one. This extends the sample from 405 days to 534 days for the two-year contract and to 578 days for the five-year contract. For the sake of brevity $\underline{\text { Table } 9}$ only shows the results of reproducing earlier Table 6 Panel B, which includes market states, macroeconomic news and order flow. $^{14}$

As before, market states are highly significant with the expected signs. Among news, there is hardly any change. U.S. news show the same pattern as they mainly increase the in-

\footnotetext{
${ }^{14}$ Splitting the data set into two subsamples, days with either a rank of one or a rank of two, reveals no structural differences. The null hypothesis of equal coefficients in both subsamples, $H_{0}:\left[b_{1,1} \ldots b_{1, n}\right]=\left[b_{2,1} \ldots b_{2, n}\right]$, is not rejected at the ten percent interval.
} 
formation share of the Bund future. Especially FOMC meetings keep their strong impact. Nonfarm payroll employment, the most important macroeconomic announcement, still improves the importance of the two- and five-year contract. Similar findings apply to the Euro Area and German news. Finally, a higher share of order flow increases the information share of the respective future contract.

\subsection{The joint analysis of cointegrated and non-cointegrated days}

In order to consider all days in the examinations, we first analyze lead-lag-relations between the three future contracts on those days without cointegration. In a second step we bring together the results of information shares and lead-lag-relations. Overall this holistic examination supports the above gained insights.

For the lead-lag-relations we conduct a VAR-approach to yield changes. In a formal expression the model includes a constant $\alpha$ and lagged yield changes of the three contracts to explain current yield changes, $\Delta y_{t}$,

$$
\left[\begin{array}{c}
\Delta y_{t, 2-\text { year }} \\
\Delta y_{t, 5 \text {-year }} \\
\Delta y_{t, 10-\text { year }}
\end{array}\right]=\left[\begin{array}{l}
a_{1} \\
a_{2} \\
a_{3}
\end{array}\right]+\left[\begin{array}{lll}
\beta_{1,1} & \beta_{1,2} & \beta_{1,3} \\
\beta_{2,1} & \beta_{2,2} & \beta_{2,2} \\
\beta_{3,1} & \beta_{3,2} & \beta_{3,3}
\end{array}\right] \times \sum_{n=1}^{N}\left[\begin{array}{c}
\Delta y_{t-n, 2-\text { year }} \\
\Delta y_{t-n, 5-\text { year }} \\
\Delta y_{t-n, 10-\text { year }}
\end{array}\right]+\left[\begin{array}{c}
\varepsilon_{t, 2 \text {-year }} \\
\varepsilon_{t, 5-\text { year }} \\
\varepsilon_{t, 10-\text { year }}
\end{array}\right]
$$

We test the contribution power of contract $j$ to price discovery in contract $i(i \neq j)$ with a Wald Test which compares an unrestricted (17) with a restricted model. In the restricted model the off-diagonal coefficient $\beta_{i, j}$ is set to zero. If the null hypothesis of no contribution of contract $\mathrm{j}$ is rejected, this contract at least partly leads the price discovery process (Forte and Pẽna, 2009).

A further step combines the results of information shares and lead-lag-relations. The methodology is based on Forte and Pẽna (2009) and compares each possible pair of contracts. The leadership dummy variable of contract i compared to contract $j, D(i, j)$ takes a value of 1 if 
contract $\mathrm{i}$ has either (1) a higher information share or has (2) a price impact on future yield changes of contract $\mathrm{j}$, but not vice versa.

Table 10 presents the sum and the averages of the dummy variables. Again, we see the same dominance structure as before. The Bund future is on average the major contributor to yield innovations. On more than $60 \%$ of the days the 10 -year contract leads the price discovery process compared to both, the two- and five-year contract. The null hypothesis of a mean below $50 \%$ is rejected in both cases.

However, in nearly $30 \%$ of the cases the shorter maturity contracts are the main information processors. These days might be affected by a general weakness of the ten-year contract. We exclusively test for these days for equal means of the dummy variables of the twoyear and five-year future, each compared to the ten-year's one. Under the null hypothesis we expect that the leadership of the two-year contract goes along with a leadership of the fiveyear contract, and vice versa. Although both subsamples reveal a strong relation of the leading roles of the shorter maturities we reject the null hypothesis of equal means at the one percent level. ${ }^{15}$

Our results are in line with implications derived from the information share approach and support the view that not only the strength or weakness of the Bund future matters for the price discovery process. Rather, the two- and five-year futures are on their own able to attract information which brings them into an outstanding role.

\section{Conclusions}

Our study analyzes price discovery in the Euro bond future market by applying the information share approach. We contribute to the literature in two ways: first, we extend the

\footnotetext{
${ }^{15}$ The t-statistic of equal means in the case of a leadership role of the 2-year future is 7.96 and for the 5-year future 7.37.
} 
price discovery analysis in the European market to several future contracts. Second, we extend the so far considered determinants of information shares by also making use of order flow data. Both contributions reveal interesting insights.

In covering the European bond market, we calculate information shares for the Bund, i.e. the ten-year German bond future, versus two other - so far neglected - future contracts, i.e. the two-year Schatz and the five-year Bobl. We find that the Bund is indeed the single most important contract for price discovery but that it does not dominate to an extent that the two other contracts would become unimportant. By contrast, there are many days, where the Bund is less important than another future contract.

In extending the determinants of information shares we complement market state and macroeconomic news variables by so far neglected order flow variables. Order flow has often been found to be a relevant measure in analyzing information flows in financial markets, so that it seems a natural extension to consider it as determinant of information shares too. Indeed, it proves to be an important determinant beyond the earlier variables. In particular, order flow is rather more important than macroeconomic news in understanding shifts in information shares between the Bund and the other future contracts. 


\section{References}

Ahn, Hee-John, Jun Cai and Yan-Leung Cheung (2002), What moves German Bund futures contracts on the Eurex?, Journal of Futures Markets 22:7,679-696.

Anand, Amber and Sugato Chakravarty (2007), Stealth trading in options markets, Journal of Financial and Quantitative Analysis 42:1, 167-188.

Andersen, Torben G. and Tim Bollerslev (1998), Deutsche Mark-Dollar volatility: Intraday activity patterns, macroeconomic announcements, and longer run dependencies, Journal of Finance, 53:1, 219-265.

Andersen, Torben G., Tim Bollerslev, Francis X. Diebold and Clara Vega (2007), Real-time price discovery in global stock, bond and foreign exchange markets, Journal of International Economics, 73:2, 251-277.

Andersson, Magnus, Lars Jul Overby and Szabolcs Sebestyén (2009), Which news moves the Euro Area Bond Market?, German Economic Review, 10:1, 1-31.

Baillie, Richard T., G. Geoffrey Booth, Yiuman Tse and Tatyana Zabotina (2002), Price discovery and common factor models, Journal of Financial Markets, 5:3, 309-321.

Balduzzi, Pierluigi, Edwin J. Elton and Clifton Green (2001), Economic News and Bond Prices: Evidence from the U.S. Treasury Market, Journal of Financial and Quantitative Analysis, 36:4, 523-43.

Bandi, Federico M. and Jeffrey R. Russell (2006), Separating microstructure noise from volatility, Journal of Financial Economics 79:3, 655-692.

Barclay, Michael J. and Jerold B. Warner (1993), Stealth trading and volatility: Which trades move prices?, Journal of Financial Economics, 34:3, 281-305. 
Brandt, Michael and Kenneth A. Kavajecz (2004), Price discovery in the U.S. treasury market: The impact of orderflow and liquidity on the yield curve, Journal of Finance, 59:6, 2623-2654.

Brandt, Michael, Kenneth Kavajecz and Shane Underwood (2007), Price discovery in the Treasury futures market, Journal of Futures Markets, 27:11, 1021-1051.

Campbell, Bryan and Scott Hendry (2007), Price discovery in Canadian and U.S. 10-year government bond markets, Bank of Canada Working Paper 2007-43.

Chakravarty, Sugato (2001), Stealth-trading: Which traders' trades move stock prices?, Journal of Financial Economics, 61:2, 289-307.

Chakravarty, Sugato, Huseyin Gulen and Stewart Mayhew (2004), Informed trading in stock and option markets, Journal of Finance, 59:3, 1235-1258.

Chen, Yu-Lun and Yin-Feng Gau (2010), News announcements and price discovery in foreign exchange spot and futures markets, forthcoming in: Journal of Banking \& Finance.

Christie-David, Rohan, Mukesh Chaudhry and Walayet Khan (2002), News releases, market integration and market leadership, Journal of Financial Research 25:2, 223-245.

Covrig, Vicentiu, David K. Ding and Buen Sin Low (2004), The contribution of a satellite market to price discovery: Evidence from the Singapore exchange, Journal of Futures Markets, 24:10, 981-1004.

de Jong, Frank (2002), Measures of contributions to price discovery: a comparison, Journal of Financial Markets, 5:3, 323-327.

Dunne, Peter G., Michael J. Moore and Richard Portes (2007), Benchmark status in fixedincome asset markets, Journal of Business Finance and Accounting, 34:9/10, 16151634. 
Ehrmann, Michael and Marcel Fratzscher (2005), Equal size, equal role? Interest rate interdependence between the Euro Area and the United States, Economic Journal 115:506, 928-948.

Engle, Robert F. and Clive W.J. Granger (1987). Cointegration and error-correction: representation, estimation, and testing, Econometrica, 55:2, 251-276.

Evans, Martin D.D. and Richard K. Lyons (2008), How is macro news transmitted to exchange rates?, Journal of Financial Economics, 88:1, 26-50.

Faust, Jon, John H. Rogers, Shing-Yi B. Wang and Jonathan H. Wright (2007), The highfrequency response of exchange rates and interest rates to macroeconomic announcements, Journal of Monetary Economics 54:4, 1051-1068.

Fleming, Michael J. (2003), Measuring treasury market liquidity, Federal Reserve Bank of New York Economic Policy Review, 9:3, 83-108.

Fleming, Michael J. and Eli M. Remolona (1997), What moves the Bond market?, Federal Reserve Bank of New York Economic Policy Review, 3:4, 31-50.

Fleming, Michael J. and Eli M. Remolona (1999), What moves bond prices?, Journal of Portfolio Management, 25:4, 28-38.

Forte, Santiago and Juan Ignacio Pẽna (2009), Credit spreads: An empirical analysis of the information content of stocks, bonds, and CDS, Journal of Banking and Finance, 33:11, 2013-2025.

Goldberg, Linda and Deborah Leonard (2003), What Moves Sovereign Bond Markets? The Effects of Economic News on U.S. and German Yields, Current Issues in Economics and Finance 9:9, Federal Reserve Bank of New York.

Gonzalo, Jesus and Clive Granger (1995), Estimation of common long-memory components in cointegrated systems, Journal of Business and Economic Statistics, 13:1, 27-35. 
Green, Clifton (2004), Economic news and the impact of trading on bond prices, Journal of Finance, 59:3, 1201-1234.

Hall Anthony D., Heather M. Anderson and Clive W. J. Granger (1992), A cointegration analysis of Treasury Bill yields, Review of Economics and Statistics 74:1, 116-126.

Harris, Frederick H. deB., Thomas H. McInish, and Robert A. Wood (2002), Security price adjustment across exchanges: An investigation of common factor components for Dow stocks, Journal of Financial Markets, 5:3, 277-308.

Hasbrouck, Joel (1991a), The summary informativeness of stock trades: an econometric analysis, Review of Financial Studies, 4:3, 571-595.

Hasbrouck, Joel (1991b), Measuring the information content of stock trades, Journal of Finance, 46:1, 179-207.

Hasbrouck, Joel (1995), One security, many markets: Determining the contributions to price discovery, Journal of Finance, 50:4, 1175-1199.

Hasbrouck, Joel (2002), Stalking the "efficient price" in market microstructure specifications: an overview, Journal of Financial Markets, 5:3, 329-339.

Hasbrouck, Joel (2007), Empirical Market Microstructure, Oxford University Press.

Hautsch, Nikolaus and Dieter Hess (2007), Bayesian learning in financial markets: Testing for the relevance of information precision in price discovery, Journal of Financial and Quantitative Analysis, 42:1, 189-208.

Johansen, Soren (1988), Statistical analysis of co-integration vectors, Journal of Economic Dynamics and Control, 12:2-3, 231-254.

Johansen, Soren (1991), Estimation and hypotheses testing of cointegration vectors in Gaussian vector autoregressive models, Econometrica, 59:6, 1551-1580. 
Killeen, William P., Richard K. Lyons and Micheal J. Moore (2006), Fixed versus flexible: Lessons from EMS order flow, Journal of International Money and Finance, 25:4, 551579.

Lehmann, Bruce N. (2002), Some desiderata for the measurement of price discovery across markets, Journal of Financial Markets, 5:3, 259-276.

Lien, Donald and Keshab Shrestha (2009), A new information share measure, Journal of Futures Markets 29:4, $377-395$.

Menkhoff, Lukas and Maik Schmeling (2010), Whose trades convey information? Evidence from a cross-section of traders, Journal of Financial Markets, 13:1, 101-128.

Menkveld, Albert J., Yiu Chung Cheung and Frank de Jong (2004), Euro area sovereign yield dynamics: the role of order imbalance, ECB Working Paper No. 385.

Menkveld, Albert J., Asani Sarkar and Michel van der Wel (2007), Customer flow, intermediaries, and the discovery of the equilibrium riskfree rate, Federal Reserve Bank of New York Staff Report No. 307.

Mizrach, Bruce and Chris Neely (2008), Information shares in the US treasury market, Journal of Banking and Finance, 32:7, 1221-1233.

Pasquariello, Paolo and Clara Vega (2007), Informed and strategic order flow in the bond markets, Review of Financial Studies, 20:6, 1975-2019.

Schlusche, Bernd (2009), Price Formation in Spot and Futures Markets: Exchange Traded Funds vs. Index Futures, Journal of Derivatives 17:2, 26-40.

Theissen, Erik (2002), Price discovery in floor and screen trading systems, Journal of Empirical Finance, 9:4, 2002, 455-474. 
Tswei, Keshin and Jing-yi Lai (2009), Information contents misjudged: Digressive convergence to equilibrium in cointegrated prices, Review of Financial Economics 18:4, 183189.

Upper, Christian and Thomas Werner (2007), The tail wags the dog: time-varying information shares in the Bund market, BIS Working Paper 224.

Underwood, Shane (2009), The cross-market information content of stock and bond order flow, Journal of Financial Markets, 12:2, 268-289.

Yan, Bingcheng and Eric Zivot (2010), A structural analysis of price discovery measures, Journal of Financial Markets 13:1, 1-19. 


\section{Table 1: Eurex future trading data: summary statistic}

This table shows descriptive statistics for the underlying data set. Transactions and quotes are collected from the Eurex trading platform and cover the time range between June 01st, 2004 and June 7th, 2007. Market relevant information includes the future's specific return (multiplied with 100), the quantity and the number of buys, sells, order flow and the trading volume. The columns contain the estimated means, standard deviations, maximums, minimums and the first order autocorrelation for the two-, five- and ten-year futures. A ' $*$ ', ' $* *$ ' or ' $* * *$ ' shows the significance of the first-order autocorrelation at the $10 \%, 5 \%$ or the $1 \%$ level.

\begin{tabular}{|c|c|c|c|c|c|c|}
\hline & mean & stdev. & $\max$. & min. & $\rho(1)$ & p-value \\
\hline & \multicolumn{6}{|c|}{ 2-year } \\
\hline daily return & -0.0035 & 0.001 & 0.003 & -0.004 & 0.003 & 0.92 \\
\hline number of buys per day & 1,931 & 872 & 7,633 & 299 & 0.574 & $0.00 * * *$ \\
\hline volume of buys per day & 233,547 & 88,613 & 632,714 & 29,940 & 0.387 & $0.00 * * *$ \\
\hline number of sells per day & $-1,974$ & 920 & -173 & $-7,225$ & 0.587 & $0.00 * * *$ \\
\hline volume of sells per day & $-235,884$ & 91,877 & $-25,071$ & $-655,901$ & 0.393 & $0.00 * * *$ \\
\hline binary order flow per day & -43 & 439 & 1,967 & $-2,645$ & 0.183 & $0.00 * * *$ \\
\hline quantitative order flow per day & $-2,337$ & 31,532 & 138,017 & $-119,220$ & 0.070 & $0.03 * *$ \\
\hline binary trading volume per day & 3,906 & 1,738 & 14,558 & 472 & 0.606 & $0.00 * * *$ \\
\hline \multirow[t]{2}{*}{ traded contracts per day } & 469,432 & 177,745 & $1,288,615$ & 55,011 & 0.400 & $0.00 * * *$ \\
\hline & \multicolumn{6}{|c|}{ 5-year } \\
\hline daily return & -0.0100 & 0.002 & 0.006 & -0.010 & 0.007 & 0.82 \\
\hline number of buys per day & 3,617 & 1,259 & 11,131 & 666 & 0.511 & $0.00 * * *$ \\
\hline volume of buys per day & 261,847 & 88,531 & 556,966 & 38,302 & 0.380 & $0.00 * * *$ \\
\hline number of sells per day & $-3,636$ & 1,343 & -553 & $-10,960$ & 0.527 & $0.00 * * *$ \\
\hline volume of sells per day & $-262,857$ & 90,448 & $-29,114$ & $-605,430$ & 0.375 & $0.00 * * *$ \\
\hline binary order flow per day & -19 & 497 & 2,187 & $-1,999$ & 0.004 & 0.91 \\
\hline quantitative order flow per day & $-1,010$ & 24,332 & 83,260 & $-85,443$ & 0.023 & 0.47 \\
\hline binary trading volume per day & 7,253 & 2,555 & 22,091 & 1,219 & 0.539 & $0.00 * * *$ \\
\hline \multirow[t]{2}{*}{ traded contracts per day } & 524,704 & 177,328 & $1,162,396$ & 67,416 & 0.384 & $0.00 * * *$ \\
\hline & \multicolumn{6}{|c|}{ 10-year } \\
\hline daily return & -0.0100 & 0.003 & 0.010 & -0.014 & 0.012 & 0.70 \\
\hline number of buys per day & 8,121 & 3,628 & 25,432 & 1,135 & 0.696 & $0.00 * * *$ \\
\hline volume of buys per day & 477,972 & 167,034 & $1,091,272$ & 56,528 & 0.441 & $0.00 * * *$ \\
\hline number of sells per day & $-8,169$ & 3,771 & $-1,035$ & $-24,357$ & 0.697 & $0.00 * * *$ \\
\hline volume of sells per day & $-481,085$ & 173,386 & $-42,819$ & $-1,271,967$ & 0.440 & $0.00 * * *$ \\
\hline binary order flow per day & -48 & 770 & 3,602 & $-3,976$ & -0.059 & $0.06^{*}$ \\
\hline quantitative order flow per day & $-3,113$ & 42,736 & 138,790 & $-248,798$ & 0.122 & $0.00 * * *$ \\
\hline binary trading volume per day & 16,290 & 7,361 & 49,789 & 2,170 & 0.704 & $0.00 * * *$ \\
\hline traded contracts per day & 959,056 & 337,787 & $2,295,136$ & 101,527 & 0.445 & $0.00 * * *$ \\
\hline
\end{tabular}




\section{Table 2: Augmented Dickey-Fuller test and Johansen rank test}

The table reports the average results of the Augmented Dickey-Fuller-test and the Johansen rank test. The appropriate lag-length is determined by the likelihood ratio test and is in both cases on average four. The one (five / ten) percent critical value of the Augmented Dickey-Fuller-test is -3.458 (-2.871 / $-2.5937)$. The $90 \%$ critical values of the trace and eigenvalue test of the Johansen rank test are reported in brackets.

\begin{tabular}{|c|c|c|c|c|}
\hline \multicolumn{5}{|c|}{ Augmented Dickey-Fuller-Test } \\
\hline maturity & \multicolumn{4}{|c|}{ ADF t-statistic } \\
\hline 2 -year & \multicolumn{4}{|c|}{-1.9728} \\
\hline 5-year & \multicolumn{4}{|c|}{0.4882} \\
\hline 10-year & \multicolumn{4}{|c|}{0.4956} \\
\hline \multicolumn{5}{|c|}{ Johansen rank test } \\
\hline & \multicolumn{4}{|c|}{ maturity } \\
\hline & \multicolumn{4}{|c|}{ 2-year, 5-year and 10-year } \\
\hline hypothesis & \multicolumn{2}{|c|}{ trace } & \multicolumn{2}{|c|}{ eigenvalue } \\
\hline $\mathrm{r}=0$ & 136.18 & (27.07) & 108.98 & $(18.89)$ \\
\hline $\mathrm{r}=1$ & 27.20 & $(13.43)$ & 25.74 & $(12.30)$ \\
\hline \multirow[t]{3}{*}{$r=2$} & 1.46 & $(2.71)$ & 1.46 & $(2.71)$ \\
\hline & \multicolumn{4}{|c|}{ maturity } \\
\hline & \multicolumn{4}{|c|}{ 2-year and 10-year } \\
\hline hypothesis & \multicolumn{2}{|c|}{ trace } & \multicolumn{2}{|c|}{ eigenvalue } \\
\hline$r=0$ & 51.37 & $(13.43)$ & 66.54 & $(12.30)$ \\
\hline \multirow[t]{3}{*}{$\mathrm{r}=1$} & 2.64 & $(2.71)$ & 2.52 & $(2.71)$ \\
\hline & \multicolumn{4}{|c|}{ maturity } \\
\hline & \multicolumn{4}{|c|}{ 5-year and 10-year } \\
\hline hypothesis & \multicolumn{2}{|c|}{ trace } & \multicolumn{2}{|c|}{ eigenvalue } \\
\hline$r=0$ & 48.74 & $(13.43)$ & 64.03 & $(12.30)$ \\
\hline$r=1$ & 2.63 & $(2.71)$ & 2.51 & $(2.71)$ \\
\hline
\end{tabular}




\section{Table 3: Determinants of the cointegration relationship}

The table provides t-statistics and p-value in brackets for testing structural differences in the mean on days with and without cointegration for the two- and five-year contract, each to the ten-year future. Slope is measured as the yield-spread between the maturities of two and ten years. Volume reflects traded contracts per day and the volatility is based on five-minute midquote changes.

\begin{tabular}{|c|c|c|c|c|c|c|c|}
\hline & \multicolumn{7}{|c|}{ effect } \\
\hline & \multirow{2}{*}{$\begin{array}{c}\text { slope } \\
\text { changes }\end{array}$} & \multicolumn{3}{|c|}{ volume } & \multicolumn{3}{|c|}{ volatility } \\
\hline & & 2-year & 5-year & 10 -year & 2-year & 5-year & 10-year \\
\hline \multicolumn{8}{|l|}{ 2-year } \\
\hline \multicolumn{8}{|l|}{ mean } \\
\hline days with cointegration & -0.0071 & 497,782 & 536,093 & $1,025,654$ & 975.0 & 1217.0 & 1130.7 \\
\hline days without cointegration & -0.0099 & 448,351 & 471,074 & 911,851 & 989.1 & 1294.7 & 1193.4 \\
\hline t-statistic & 0.31 & 3.56 & 4.85 & 4.25 & 0.46 & 1.83 & 1.70 \\
\hline p-value & $(0.757)$ & $(0.000)$ & $(0.000)$ & $(0.000)$ & $(0.646)$ & $(0.068)$ & $(0.089)$ \\
\hline \multicolumn{8}{|l|}{ 5-year } \\
\hline \multicolumn{8}{|l|}{ mean } \\
\hline days with cointegration & -0.0064 & 491,129 & 528,126 & $1,015,287$ & 977.6 & 1223.9 & 1131.3 \\
\hline days without cointegration & -0.0128 & 456,666 & 479,685 & 916,318 & 984.6 & 1291.9 & 1206.0 \\
\hline t-statistic & 0.67 & 2.32 & 3.37 & 3.45 & 0.21 & 1.50 & 1.91 \\
\hline p-value & $(0.501)$ & $(0.021)$ & $(0.001)$ & $(0.001)$ & $(0.833)$ & $(0.134)$ & $(0.057)$ \\
\hline
\end{tabular}

\section{Table 4: Yearly information shares}

Results below are the annual averages of the daily information shares estimated by the Hasbrouck (1995) and HMW (Harris et al, 2002) approaches. MIS reports the estimation of the modified information share (Lien and Shrestha, 2009). Lower and upper bounds of the Hasbrouck information shares depend on the order of the contracts in the Cholesky decomposition. The mid-point is the average of all possible orders. We report estimated and normalized HMW information shares. Days with a rank of less than two are dropped out which reduced our data set to 405 observations.

\begin{tabular}{|c|c|c|c|c|c|c|}
\hline \multirow{2}{*}{ maturity } & \multirow{2}{*}{\multicolumn{2}{|c|}{ information share }} & \multicolumn{4}{|c|}{ year } \\
\hline & & & 2004 & 2005 & 2006 & 2007 \\
\hline \multirow[t]{6}{*}{ 2-year } & \multirow[t]{3}{*}{ Hasbrouck } & lower bound & $13.61 \%$ & $17.39 \%$ & $13.89 \%$ & $13.24 \%$ \\
\hline & & mid point & $15.74 \%$ & $18.92 \%$ & $16.10 \%$ & $14.82 \%$ \\
\hline & & upper bound & $18.25 \%$ & $20.45 \%$ & $18.40 \%$ & $16.66 \%$ \\
\hline & \multicolumn{2}{|l|}{ MIS } & $15.89 \%$ & $18.83 \%$ & $15.87 \%$ & $15.05 \%$ \\
\hline & \multicolumn{2}{|l|}{ HMW } & $15.81 \%$ & $21.16 \%$ & $17.91 \%$ & $19.38 \%$ \\
\hline & \multicolumn{2}{|c|}{ HMW (normalized) } & $18.81 \%$ & $23.01 \%$ & $20.78 \%$ & $21.60 \%$ \\
\hline \multirow[t]{6}{*}{ 5-year } & \multirow[t]{3}{*}{ Hasbrouck } & lower bound & $20.45 \%$ & $21.79 \%$ & $21.05 \%$ & $14.41 \%$ \\
\hline & & mid point & $25.78 \%$ & $25.56 \%$ & $26.91 \%$ & $20.42 \%$ \\
\hline & & upper bound & $29.60 \%$ & $28.59 \%$ & $30.98 \%$ & $24.40 \%$ \\
\hline & \multicolumn{2}{|l|}{ MIS } & $24.72 \%$ & $25.00 \%$ & $25.73 \%$ & $19.21 \%$ \\
\hline & \multicolumn{2}{|l|}{ HMW } & $24.12 \%$ & $26.01 \%$ & $25.40 \%$ & $21.57 \%$ \\
\hline & \multicolumn{2}{|c|}{ HMW (normalized) } & $24.10 \%$ & $25.29 \%$ & $24.45 \%$ & $21.59 \%$ \\
\hline \multirow[t]{6}{*}{ 10-year } & \multirow[t]{3}{*}{ Hasbrouck } & lower bound & $54.92 \%$ & $52.54 \%$ & $52.87 \%$ & $60.85 \%$ \\
\hline & & mid point & $58.48 \%$ & $55.52 \%$ & $56.98 \%$ & $64.75 \%$ \\
\hline & & upper bound & $63.74 \%$ & $59.41 \%$ & $63.28 \%$ & $71.00 \%$ \\
\hline & \multicolumn{2}{|l|}{ MIS } & $59.39 \%$ & $56.17 \%$ & $58.39 \%$ & $65.73 \%$ \\
\hline & \multicolumn{2}{|l|}{ HMW } & $60.07 \%$ & $52.83 \%$ & $56.70 \%$ & $59.05 \%$ \\
\hline & \multicolumn{2}{|c|}{ HMW (normalized) } & $57.08 \%$ & $51.70 \%$ & $54.77 \%$ & $56.81 \%$ \\
\hline \multicolumn{3}{|c|}{ number of observations } & 82 & 124 & 132 & 67 \\
\hline
\end{tabular}


Figure 1: Daily information shares of the two-, five- and ten-year future

This figure shows the information shares in the two-, five and ten-year German bond future. The calculation is based on the Hasbrouck (1995) approach on a daily basis. Our data set starts at June 2004 and ends at June 2007.

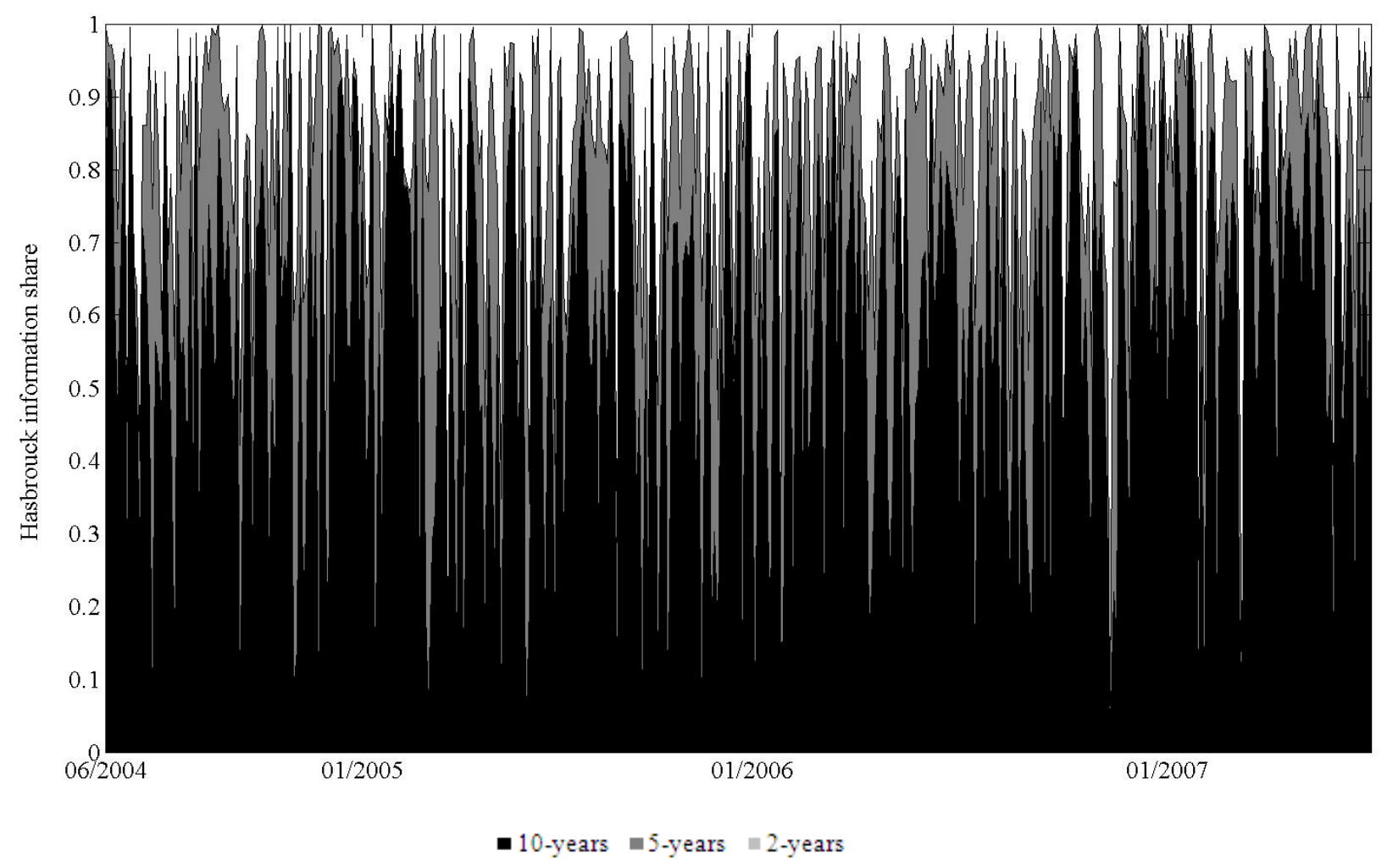


Table 5: Responses of information shares to liquidity related variables

The table mirrors the regression results of microstructure variables on daily information shares of the two-, five- and ten-year future, which takes the following form: $\ln \left(I S_{i, t} /\left(1-I S_{i, t}\right)\right)=c+b_{1} T T D+b_{2} D D+b_{3} O D D+b_{4} \ln \left(S_{i, t}\right)+b_{5} \ln \left(\operatorname{Vol}_{i, t}\right)+b_{6} \ln \left(R V_{i, t}\right)+\varepsilon_{t}$, with i representing the maturities, c the intercept term, TTD the time-to-maturity, DD a dummy variable with a value of one at each delivery day and OOD a dummy variable with a values of one at each options' delivery day. $S, V o l$ and $R V$ are individual shares of the marketwide average five minute quoted spread, the number of traded futures per day and RV midquote's realized volatility for the given day. The $10 \%(5 \%, 1 \%)$ significance level is marked with a $*(* * / * * *)$.

\begin{tabular}{|c|c|c|c|c|c|c|c|c|c|}
\hline \multirow[b]{3}{*}{ variable } & \multicolumn{3}{|c|}{ Hasbrouck information share } & \multicolumn{3}{|c|}{ modified information share } & \multicolumn{3}{|c|}{ HMW information share } \\
\hline & \multicolumn{3}{|c|}{ maturity } & \multicolumn{3}{|c|}{ maturity } & \multicolumn{3}{|c|}{ maturity } \\
\hline & 2-year & 5-year & 10-year & 2-year & 5-year & 10-year & 2-year & 5-year & 10-year \\
\hline constant & $-5.1699 * * *$ & $5.2085^{* *}$ & $-3.5840 * * *$ & $-7.1510 * * *$ & $5.0709 * *$ & $-3.4719 * *$ & $-4.1252 * * *$ & 1.4916 & $-2.9428 * *$ \\
\hline TTD & $0.0034 * * *$ & $0.0028 * *$ & $-0.0027 * * *$ & $0.0036 * * *$ & $0.0039 * *$ & $-0.0028 * * *$ & $0.0018 * * *$ & $0.0022 * * *$ & $-0.0017 * * *$ \\
\hline DD & $-0.3512 * *$ & -0.0756 & $0.7325 * * *$ & $-0.2887 *$ & -0.0651 & $0.7573 * * *$ & -0.1385 & -0.0801 & $0.3997 * * *$ \\
\hline options' DD & $-0.5571 *$ & $-0.9138 * * *$ & $0.7591 * *$ & $-0.5488 *$ & $-0.9325 * * *$ & $0.7754 * *$ & -0.2369 & $-0.4587 * * *$ & $0.4072 * * *$ \\
\hline \multicolumn{10}{|l|}{$\underline{\text { trading related }}$} \\
\hline spread & $-4.1201 * * *$ & $6.2239 * * *$ & $-7.0834 * * *$ & $-5.4623 * * *$ & $6.2473 * * *$ & $-7.2131 * * *$ & $-2.2031 * * *$ & $3.2953 * * *$ & $-4.4603 * * *$ \\
\hline volume & $2.3578 * * *$ & $1.5346 * * *$ & $4.4477 * * *$ & $2.4158 * * *$ & $1.5212 * * *$ & $4.6864 * * *$ & $1.2065 * * *$ & $0.7400 * * *$ & $2.1019 * * *$ \\
\hline volatility & 0.2109 & $-0.9052 *$ & $-1.2163 * * *$ & 0.2720 & -0.8497 & $-1.2236 * * *$ & $-0.2115^{*}$ & $-1.0301 * * *$ & $-1.0933 * * *$ \\
\hline adjusted $\mathrm{R}^{\mathbf{2}}$ & $3.4 \%$ & $1.8 \%$ & $4.9 \%$ & $3.5 \%$ & $1.3 \%$ & $4.9 \%$ & $2.8 \%$ & $2.5 \%$ & $4.8 \%$ \\
\hline
\end{tabular}




\section{Table 6a: Impact parameters on daily information shares' fluctuation}

Results report regression results of trend variables, news and log-shares of microstructure variables on logarithmic transformations of the daily information shares of the two-, five- and ten-year future. Table $6 \mathrm{a}(6 \mathrm{~b} / 6 \mathrm{c})$ refers to the Hasbrouck information share (Modified information share / HMW information share). Robust standard errors (Newey-West, 1987) are used. The intercept term, time-to-maturity and delivery days of futures and options, which are included in Panel A and B, are not reported for brevity. News variables represent the absolute values of the difference between the realized and expected value, each standardized by dividing by its standard deviation. The $10 \%(5 \%, 1 \%)$ significance level is marked with a $*(* * / * * *)$.

\begin{tabular}{|c|c|c|c|c|c|c|}
\hline \multirow[b]{3}{*}{ variable } & \multicolumn{6}{|c|}{ Hasbrouck information share } \\
\hline & \multicolumn{2}{|c|}{ 2-year } & \multicolumn{2}{|c|}{ 5-year } & \multicolumn{2}{|c|}{ 10-year } \\
\hline & Panel A & Panel B & Panel A & Panel B & Panel A & Panel B \\
\hline \multicolumn{7}{|l|}{ trading-related } \\
\hline spread & & $-3.507 * * *$ & & $6.203 * * *$ & & $-6.732 * * *$ \\
\hline volume & & $2.049 * * *$ & & $1.759 * *$ & & $4.352 * * *$ \\
\hline volatility & & $-0.362 * * *$ & & $-0.845^{*}$ & & $-1.251 * * *$ \\
\hline \multicolumn{7}{|l|}{$\underline{\text { macroeconomic news }}$} \\
\hline \multicolumn{7}{|l|}{$\underline{\mathrm{US}}$} \\
\hline nonfarm payroll employment & $0.516 * * *$ & $0.387 * * *$ & $0.533 * * *$ & $0.464 * * *$ & $-0.932 * * *$ & $-0.784 * * *$ \\
\hline jobless claims & -0.062 & -0.141 & $0.141 *$ & 0.067 & 0.008 & 0.115 \\
\hline PPI & $-0.182 * *$ & -0.137 & 0.166 & $0.170^{*}$ & 0.043 & -0.007 \\
\hline GDP & 0.229 & $0.293^{*}$ & 0.208 & 0.174 & -0.202 & -0.345 \\
\hline retail sales & $-0.544 * * *$ & $-0.291 *$ & $-0.229 *$ & -0.163 & $0.625 * * *$ & $0.475 * * *$ \\
\hline CPI & $-0.508 * * *$ & $-0.523^{* * *}$ & -0.023 & -0.107 & $0.394 * * *$ & $0.383 * * *$ \\
\hline FOMC & $-0.230 * * *$ & $-0.304 * * *$ & 0.046 & 0.037 & $0.474 * * *$ & $0.554 * *$ \\
\hline \multicolumn{7}{|l|}{ Euro Area } \\
\hline jobless claims & $-0.304 * * *$ & -0.075 & 0.001 & 0.003 & $0.300 * * *$ & $0.171 * *$ \\
\hline PPI & $-0.215^{* * *}$ & $-0.264 * * *$ & -0.074 & -0.128 & $0.205^{* *}$ & 0.175 \\
\hline GDP & -0.1031 & -0.027 & $1.569 * * *$ & $1.827 * * *$ & -0.211 & -0.291 \\
\hline retail sales & 0.377 & $0.515^{* *}$ & $0.776^{* * *}$ & $0.821 * * *$ & $-0.566 * * *$ & $-0.589 * * *$ \\
\hline CPI & $0.411 * * *$ & $0.426 * * *$ & 0.110 & 0.009 & -0.140 & -0.063 \\
\hline ECB conferences & $0.797 * * *$ & $0.706^{* * *}$ & -0.011 & -0.095 & $-0.302 *$ & $-0.201 * * *$ \\
\hline \multicolumn{7}{|l|}{ German } \\
\hline jobless claims & $0.408 * *$ & 0.312 & $0.327 * * *$ & $0.274 * * *$ & $-0.525 * * *$ & $-0.509 * * *$ \\
\hline PPI & 0.075 & -0.060 & $-0.123^{*}$ & -0.131 & 0.1663 & 0.145 \\
\hline GDP & $0.448 * * *$ & $0.358 * * *$ & $-1.227 * * *$ & $-1.408 * * *$ & 0.071 & 0.061 \\
\hline retail sales & 0.087 & $0.200 *$ & -0.016 & -0.128 & -0.117 & -0.139 \\
\hline CPI & 0.092 & 0.129 & $0.249 * * *$ & $0.195^{* * *}$ & $-0.091 * * *$ & $-0.183 * * *$ \\
\hline industrial production & 0.1918 & $0.338 * *$ & $-0.220^{*}$ & $-0.294 * *$ & 0.214 & 0.129 \\
\hline ifo business climate & $-1.666^{* * *}$ & $-1.547 * * *$ & $-1.337 * * *$ & $-1.382 * * *$ & $1.637 * * *$ & $1.594 * * *$ \\
\hline \multicolumn{7}{|l|}{ informed trading related } \\
\hline \multicolumn{7}{|l|}{ order flow } \\
\hline non-announcement & & -0.137 & & -0.034 & & -0.010 \\
\hline announcement & & $0.227 * * *$ & & $0.067 * * *$ & & $0.248 * * *$ \\
\hline \multicolumn{7}{|l|}{ unexpected order flow } \\
\hline non-announcement & & -0.070 & & 0.041 & & $0.391 * *$ \\
\hline announcement & & $-0.256 * * *$ & & $-0.169 * * *$ & & -0.016 \\
\hline \multicolumn{7}{|l|}{ medium-size order flow } \\
\hline non-announcement & & 1.196 & & -0.600 & & -0.541 \\
\hline announcement & & $1.152^{*}$ & & -0.523 & & -0.580 \\
\hline adjusted $\mathrm{R}^{2}$ & $0.7 \%$ & $4.3 \%$ & $2.1 \%$ & $2.1 \%$ & $3.1 \%$ & $6.8 \%$ \\
\hline
\end{tabular}


Table 6b: Impact parameters on daily information shares' fluctuation

\begin{tabular}{|c|c|c|c|c|c|c|}
\hline \multirow[b]{3}{*}{ variable } & \multicolumn{6}{|c|}{ Modified informartion share } \\
\hline & \multicolumn{2}{|c|}{ 2-year } & \multicolumn{2}{|c|}{ 5-year } & \multicolumn{2}{|c|}{ 10-year } \\
\hline & Panel A & Panel B & Panel A & Panel B & Panel A & Panel B \\
\hline \multicolumn{7}{|l|}{ trading-related } \\
\hline spread & & $-4.945 * * *$ & & $5.625 * * *$ & & $-6.826 * * *$ \\
\hline volume & & $2.066 * * *$ & & $2.140 * *$ & & $4.629 * * *$ \\
\hline volatility & & $-0.356^{* *}$ & & -0.725 & & $-1.267 * * *$ \\
\hline \multicolumn{7}{|l|}{ macroeconomic news } \\
\hline \multicolumn{7}{|l|}{$\underline{\mathrm{US}}$} \\
\hline nonfarm payroll employment & $0.526 * * *$ & $0.398 * * *$ & $0.549 * * *$ & $0.477 * * *$ & $-0.932 * * *$ & $-0.773 * * *$ \\
\hline jobless claims & -0.098 & -0.184 & $0.189 * *$ & 0.111 & 0.015 & 0.129 \\
\hline PPI & $-0.459 * * *$ & $-0.411 * *$ & 0.051 & 0.051 & 0.067 & 0.019 \\
\hline GDP & 0.236 & $0.301 *$ & 0.190 & 0.153 & -0.213 & -0.353 \\
\hline retail sales & $-0.712 * * *$ & $-0.465^{* *}$ & $-0.257^{*}$ & -0.168 & $0.656 * * *$ & $0.507 * * *$ \\
\hline CPI & $-0.557 * * *$ & $-0.569 * * *$ & 0.020 & -0.067 & $0.420 * * *$ & $0.420 * * *$ \\
\hline FOMC & $-0.160 * *$ & $-0.251 * * *$ & -0.333 & -0.341 & $0.488 * * *$ & $0.574 * *$ \\
\hline \multicolumn{7}{|l|}{ Euro Area } \\
\hline jobless claims & $-0.253 * * *$ & 0.024 & 0.006 & -0.002 & $0.294 * * *$ & $0.165^{*}$ \\
\hline PPI & $-0.210 * * *$ & $-0.271 * * *$ & -0.070 & -0.126 & $0.198 * *$ & 0.170 \\
\hline GDP & -0.287 & -0.184 & $3.437 * * *$ & $3.730 * * *$ & -0.140 & -0.233 \\
\hline retail sales & 0.414 & $0.553 * *$ & $0.904 * * *$ & $0.955 * * *$ & $-0.628 * * *$ & $-0.643 * * *$ \\
\hline CPI & $0.479 * * *$ & $0.504 * * *$ & 0.144 & 0.042 & -0.162 & -0.077 \\
\hline ECB conferences & $0.856 * * *$ & $0.786^{* * *}$ & 0.098 & -0.008 & $-0.308^{*}$ & $-0.187 * * *$ \\
\hline \multicolumn{7}{|l|}{ German } \\
\hline jobless claims & $0.429 * *$ & 0.331 & $0.401 * * *$ & $0.345 * * *$ & $-0.527 * * *$ & $-0.504 * * *$ \\
\hline PPI & 0.001 & -0.144 & -0.087 & -0.093 & 0.159 & 0.146 \\
\hline GDP & $0.583 * * *$ & $0.487 * * *$ & $-2.806 * * *$ & $-3.010 * * *$ & 0.041 & 0.035 \\
\hline retail sales & 0.0923 & 0.207 & 0.021 & -0.097 & -0.108 & -0.125 \\
\hline CPI & 0.121 & $0.155^{*}$ & $0.318 * * *$ & $0.253 * *$ & $-0.088 * *$ & $-0.175^{* * *}$ \\
\hline industrial production & 0.227 & $0.381 * *$ & -0.178 & $-0.259 *$ & 0.195 & 0.113 \\
\hline ifo business climate & $-2.055^{* * *}$ & $-1.956 * * *$ & $-1.412 * * *$ & $-1.460 * * *$ & $1.777 * * *$ & $1.738 * * *$ \\
\hline \multicolumn{7}{|l|}{$\frac{\text { informed trading related }}{\text { order flow }}$} \\
\hline non-announcement & & -0.124 & & $-0.091^{*}$ & & -0.060 \\
\hline announcement & & $0.199 * * *$ & & $0.081 * * *$ & & $0.255^{* * *}$ \\
\hline \multicolumn{7}{|l|}{ unexpected order flow } \\
\hline non-announcement & & -0.091 & & 0.063 & & $0.454 * *$ \\
\hline announcement & & $-0.268 * * *$ & & $-0.194 * * *$ & & -0.018 \\
\hline \multicolumn{7}{|l|}{ medium-size order flow } \\
\hline non-announcement & & 1.252 & & -1.147 & & -0.597 \\
\hline announcement & & $1.236^{*}$ & & -1.089 & & -0.623 \\
\hline adjusted $\mathrm{R}^{2}$ & $1.4 \%$ & $5.2 \%$ & $4.3 \%$ & $4.1 \%$ & $3.1 \%$ & $7.1 \%$ \\
\hline
\end{tabular}


Table 6c: Impact parameters on daily information shares' fluctuation

\begin{tabular}{|c|c|c|c|c|c|c|}
\hline \multirow[b]{3}{*}{ variable } & \multicolumn{6}{|c|}{ HMW information share } \\
\hline & \multicolumn{2}{|c|}{ 2-year } & \multicolumn{2}{|c|}{ 5-year } & \multicolumn{2}{|c|}{ 10-year } \\
\hline & Panel A & Panel B & Panel A & Panel B & Panel A & Panel B \\
\hline \multicolumn{7}{|l|}{ trading-related } \\
\hline spread & & $-1.887 * * *$ & & $3.432 * * *$ & & $-4.078 * * *$ \\
\hline volume & & $1.178 * * *$ & & 0.846 & & $2.486^{* * *}$ \\
\hline volatility & & $-0.488 * * *$ & & $-1.026 * *$ & & $-1.056 * * *$ \\
\hline \multicolumn{7}{|l|}{ macroeconomic news } \\
\hline \multicolumn{7}{|l|}{$\underline{\mathrm{US}}$} \\
\hline nonfarm payroll employment & $0.282 * *$ & $0.258 * * *$ & $0.240 * * *$ & $0.206 * * *$ & $-0.465 * *$ & $-0.401 * * *$ \\
\hline jobless claims & 0.016 & -0.071 & 0.065 & -0.002 & -0.037 & 0.056 \\
\hline PPI & 0.003 & 0.011 & 0.022 & 0.018 & 0.055 & 0.044 \\
\hline GDP & 0.038 & 0.054 & $0.207 * * *$ & $0.168 * * *$ & -0.098 & -0.145 \\
\hline retail sales & $-0.306 * * *$ & $-0.159 *$ & -0.110 & -0.095 & $0.371 * * *$ & $0.316^{* * * *}$ \\
\hline CPI & $-0.278 * * *$ & $-0.279 * * *$ & $0.080 * *$ & 0.016 & $0.215^{* * *}$ & $0.219 * * *$ \\
\hline FOMC & $-0.073^{*}$ & $-0.080^{*}$ & 0.113 & 0.087 & 0.171 & $0.234 * *$ \\
\hline \multicolumn{7}{|l|}{ Euro Area } \\
\hline jobless claims & $-0.165 * * *$ & -0.028 & 0.032 & 0.015 & $0.145^{* *}$ & 0.083 \\
\hline PPI & $-0.108 * * *$ & $-0.135 * * *$ & -0.025 & -0.079 & $0.104 * *$ & 0.098 \\
\hline GDP & $-0.487^{*}$ & $-0.596^{* *}$ & $0.816^{* *}$ & $0.958 * * *$ & 0.005 & 0.022 \\
\hline retail sales & 0.105 & $0.188^{*}$ & $0.462 * * *$ & $0.513^{* * *}$ & $-0.286 * * *$ & $-0.309 * * *$ \\
\hline CPI & $0.305 * * *$ & $0.279 * * *$ & 0.083 & -0.022 & -0.176 & -0.098 \\
\hline ECB conferences & $0.272 * * *$ & $0.283 * *$ & 0.083 & 0.039 & -0.106 & $-0.055^{*}$ \\
\hline \multicolumn{7}{|l|}{ German } \\
\hline jobless claims & $0.253 * * *$ & $0.193 * *$ & $0.256 * * *$ & $0.209 * * *$ & $-0.340 * * *$ & $-0.317 * * *$ \\
\hline PPI & -0.003 & -0.045 & $-0.120 * *$ & -0.135 & 0.12 & 0.119 \\
\hline GDP & $0.517 * * *$ & $0.531 * * *$ & $-0.690 * * *$ & $-0.800 * * *$ & -0.062 & -0.096 \\
\hline retail sales & $0.196 * * *$ & $0.265 * * *$ & -0.042 & $-0.142 *$ & -0.149 & -0.136 \\
\hline CPI & 0.005 & 0.076 & $0.143 * * *$ & $0.124 * * *$ & -0.019 & $-0.080 * * *$ \\
\hline industrial production & $0.160 * *$ & $0.234 * * *$ & -0.038 & $-0.119 * *$ & 0.037 & 0.024 \\
\hline ifo business climate & $-0.909 * * *$ & $-0.806 * * *$ & $-0.639 * * *$ & $-0.697 * * *$ & $0.937 * * *$ & $0.949 * * *$ \\
\hline \multicolumn{7}{|l|}{$\frac{\text { informed trading related }}{\text { order flow }}$} \\
\hline non-announcement & & $-0.103 *$ & & -0.051 & & -0.120 \\
\hline announcement & & $0.191 * * *$ & & $0.042 * * *$ & & $0.162 * * *$ \\
\hline \multicolumn{7}{|l|}{ unexpected order flow } \\
\hline non-announcement & & -0.064 & & -0.003 & & 0.126 \\
\hline announcement & & $-0.137 * * *$ & & $-0.094 * * *$ & & 0.012 \\
\hline \multicolumn{7}{|l|}{ medium-size order flow } \\
\hline non-announcement & & 0.585 & & -0.234 & & $-0.543^{*}$ \\
\hline announcement & & 0.472 & & -0.305 & & $-0.919 * * *$ \\
\hline adjusted $\mathrm{R}^{2}$ & $-0.8 \%$ & $3.5 \%$ & $1.3 \%$ & $2.9 \%$ & $2.4 \%$ & $6.1 \%$ \\
\hline
\end{tabular}




\section{Table 7a: Daily information shares' fluctuation and order flows - Hasbrouck information share}

These table reports regression results of trend variables and step-by-step added logarithmic shares of order flows, unexpected and medium-sized order flow on the daily information shares. Table 6a $(6 \mathrm{~b} / 6 \mathrm{c})$ refers to the Hasbrouck information share (Modified information share / HMW information share). (Non-) Announcements variables are constructed by setting the variables on non-relevant days to zero. The intercept term, time-to-maturity and delivery days of futures and options, which are included in Panel A to D, are not reported for brevity. Robust standard errors (Newey-West, 1987) are used. The trend variables and the intercept term are not reported for brevity. The $10 \%(5 \%, 1 \%)$ significance level is marked with a $* * * / * * *)$.

\begin{tabular}{|c|c|c|c|c|c|c|c|c|c|c|c|c|}
\hline \multirow[b]{3}{*}{ variable } & \multicolumn{12}{|c|}{ Hasbrouck information share } \\
\hline & \multicolumn{4}{|c|}{ 2-year } & \multicolumn{4}{|c|}{ 5-year } & \multicolumn{4}{|c|}{ 10-year } \\
\hline & Panel A & Panel B & Panel C & Panel D & Panel A & Panel B & Panel C & Panel D & Panel A & Panel B & Panel C & Panel D \\
\hline \multicolumn{13}{|l|}{ trading-related } \\
\hline$\overline{\text { spread }}$ & & & & $-3.401 * * *$ & & & & $6.223 * * *$ & & & & $-6.820 * * *$ \\
\hline volume & & & & $2.143 * * *$ & & & & $1.935^{* * * *}$ & & & & $4.597 * * *$ \\
\hline volatility & & & & $-0.281 * *$ & & & & -0.703 & & & & $-1.161 * * *$ \\
\hline \multicolumn{13}{|l|}{ order flow } \\
\hline non-announcement & $0.107 * *$ & -0.022 & -0.045 & -0.114 & 0.024 & -0.055 & -0.043 & -0.029 & $0.189 *$ & 0.033 & 0.023 & 0.006 \\
\hline $\begin{array}{l}\text { announcement } \\
\text { unexpected order flow }\end{array}$ & $0.186^{* *}$ & $0.287 * * *$ & $0.267 * *$ & $0.303 * * *$ & -0.017 & 0.068 & $0.061^{*}$ & $0.047^{*}$ & $0.277 * * *$ & $0.379 * * *$ & $0.367 * * *$ & $0.350 * * *$ \\
\hline non-announcement & & 0.009 & -0.024 & -0.061 & & 0.019 & 0.026 & 0.046 & & $0.437 * *$ & $0.444 * *$ & $0.403 * *$ \\
\hline announcement & & $-0.207 * * *$ & $-0.240 * * *$ & $-0.283^{* * *}$ & & $-0.153 * * *$ & $-0.185 * *$ & $-0.161 * * *$ & & -0.063 & -0.055 & -0.048 \\
\hline \multicolumn{13}{|l|}{ medium-sized oder flow } \\
\hline non-announcement & & & $1.573 * *$ & 1.235 & & & -0.165 & -0.733 & & & $1.676^{* *}$ & -0.494 \\
\hline announcement & & & $1.573 * * *$ & $1.153 *$ & & & -0.118 & -0.637 & & & 1.698 & -0.559 \\
\hline adjusted $\mathrm{R}^{2}$ & $0.5 \%$ & $1.0 \%$ & $2.3 \%$ & $4.8 \%$ & $0.9 \%$ & $1.3 \%$ & $0.8 \%$ & $1.5 \%$ & $1.7 \%$ & $2.9 \%$ & $3.0 \%$ & $5.9 \%$ \\
\hline
\end{tabular}


Table 7b: Daily information shares' fluctuation and order flows - Modified information share

\begin{tabular}{|c|c|c|c|c|c|c|c|c|c|c|c|c|}
\hline \multirow[b]{3}{*}{ variable } & \multicolumn{12}{|c|}{ Modified information share } \\
\hline & \multicolumn{4}{|c|}{ 2-year } & \multicolumn{4}{|c|}{ 5-year } & \multicolumn{4}{|c|}{10 -year } \\
\hline & Panel A & Panel B & Panel C & Panel D & Panel A & Panel B & Panel C & Panel D & Panel A & Panel B & Panel C & Panel D \\
\hline \multicolumn{13}{|l|}{ trading-related } \\
\hline spread & & & & $-4.677 * * *$ & & & & $5.661 * * *$ & & & & $-6.886 * * *$ \\
\hline volume & & & & $2.136^{* * *}$ & & & & $2.298 * * *$ & & & & $4.844 * * *$ \\
\hline volatility & & & & $-0.267 *$ & & & & -0.514 & & & & $-1.175^{* * *}$ \\
\hline \multicolumn{13}{|l|}{ order flow } \\
\hline non-announcement & $0.095^{*}$ & -0.022 & -0.032 & -0.100 & -0.002 & $-0.107^{*}$ & $-0.107^{*}$ & $-0.089 *$ & 0.165 & -0.014 & -0.026 & -0.044 \\
\hline announcement & $0.192 * *$ & $0.286^{* * *}$ & $0.259 * *$ & $0.296 * * *$ & -0.028 & 0.076 & $0.078^{*}$ & $0.066^{*}$ & $0.275 * * *$ & 0.390 & 0.378 & 0.361 \\
\hline \multicolumn{13}{|l|}{ unexpected order flow } \\
\hline non-announcement & & -0.012 & -0.039 & -0.080 & & 0.048 & 0.043 & 0.067 & & $0.506^{* * *}$ & 0.512 & 0.468 \\
\hline announcement & & $-0.210 * * *$ & $-0.251 * * *$ & $-0.297 * * *$ & & $-0.172 * * *$ & $-0.216^{* * *}$ & $-0.175 * * *$ & & $-0.066^{* *}$ & $-0.057 * * *$ & -0.050 \\
\hline \multicolumn{13}{|l|}{ medium-sized oder flow } \\
\hline non-announcement & & & $1.705^{*}$ & 1.345 & & & -0.319 & $-1.302 * *$ & & & $1.823 * * *$ & -0.502 \\
\hline announcement & & & $1.738 * * *$ & 1.294 & & & -0.326 & $-1.254 * *$ & & & $1.836^{* *}$ & -0.581 \\
\hline adjusted $\mathrm{R}^{2}$ & $0.2 \%$ & $0.6 \%$ & $1.9 \%$ & $4.6 \%$ & $0.7 \%$ & $1.1 \%$ & $0.7 \%$ & $1.0 \%$ & $1.5 \%$ & $3.1 \%$ & $3.3 \%$ & $6.1 \%$ \\
\hline
\end{tabular}

Table 7c: Daily information shares' fluctuation and order flows - HMW information shares

\begin{tabular}{|c|c|c|c|c|c|c|c|c|c|c|c|c|}
\hline \multirow[b]{3}{*}{ variable } & \multicolumn{12}{|c|}{ HMW information share } \\
\hline & \multicolumn{4}{|c|}{ 2-year } & \multicolumn{4}{|c|}{ 5-year } & \multicolumn{4}{|c|}{ 10-year } \\
\hline & Panel A & Panel B & Panel C & Panel D & Panel A & Panel B & Panel C & Panel D & Panel A & Panel B & Panel C & Panel D \\
\hline \multicolumn{13}{|l|}{ trading-related } \\
\hline$\overline{\text { spread }}$ & & & & $-1.850 * * *$ & & & & $3.333 * * *$ & & & & $-4.218 * * *$ \\
\hline volume & & & & $1.184 * * *$ & & & & $0.954 *$ & & & & $2.580 * * *$ \\
\hline volatility & & & & $-0.455^{* * *}$ & & & & $-0.905 * *$ & & & & $-1.032 * * *$ \\
\hline \multicolumn{13}{|l|}{ order flow } \\
\hline$\overline{\text { non-announcement }}$ & $0.075^{* *}$ & 0.000 & -0.041 & -0.091 & 0.022 & -0.030 & -0.048 & -0.047 & $0.028 * * *$ & -0.039 & -0.100 & $-0.112 * * *$ \\
\hline announcement & $0.139 * *$ & $0.198 * * *$ & $0.204 * *$ & $0.224 * * *$ & -0.028 & 0.027 & $0.042 * * *$ & $0.028 * *$ & $0.154^{* *}$ & 0.198 & 0.234 & 0.219 \\
\hline \multicolumn{13}{|l|}{ unexpected order flow } \\
\hline non-announcement & & 0.004 & -0.029 & -0.059 & & 0.013 & -0.010 & 0.000 & & $0.187 * * *$ & 0.152 & 0.134 \\
\hline announcement & & $-0.122 * * *$ & $-0.120 * * *$ & $-0.154 * * *$ & & $-0.099 * * *$ & -0.083 & $-0.091 * * *$ & & -0.028 & $-0.014 * * *$ & -0.007 \\
\hline \multicolumn{13}{|l|}{ medium-sized oder flow } \\
\hline non-announcement & & & 0.527 & 0.641 & & & $-0.475 * *$ & -0.352 & & & $0.501 * * *$ & -0.443 \\
\hline announcement & & & 0.449 & 0.510 & & & $-0.562 * *$ & -0.413 & & & $0.146 * *$ & -0.853 \\
\hline adjusted $\mathrm{R}^{2}$ & $0.4 \%$ & $0.9 \%$ & $1.0 \%$ & $4.6 \%$ & $0.9 \%$ & $1.6 \%$ & $1.6 \%$ & $2.6 \%$ & $1.4 \%$ & $1.8 \%$ & $1.6 \%$ & $5.5 \%$ \\
\hline
\end{tabular}




\section{Table 8: Test statistics for adding order flow to market-state variables}

This table reports the F-statistics of different Wald-test to test for a significant contribution of order flow variables to explain information shares. After controlling for market-state related variables, see Table 7, order flow, unexpected order flow and medium-sized order flow are successively and with rotating order added to the regression. We use a logarithmic transformation of the information shares, microstructure- and trading-related variables. The $10 \%(5 \%, 1 \%)$ significance level is marked with a * $(* * / * * *)$ and indicates whether this variable has to be considered beside market-state and the previous listed variables. Panel A shows results for the Hasbrouck approach, Panel B refers to the modified information share and Panel C to the HMW information share.

\begin{tabular}{|c|c|c|c|}
\hline \multirow[t]{3}{*}{$\underline{\text { Panel A }}$} & \multicolumn{3}{|c|}{ F-statistics } \\
\hline & \multicolumn{3}{|c|}{ maturity } \\
\hline & 2-year & 5-year & 10-year \\
\hline order flow & 1.44 & 0.15 & 1.62 \\
\hline unexpected order flow & $3.33 * *$ & 1.50 & $2.98 *$ \\
\hline medium-sized order flow & 0.36 & 0.36 & 0.80 \\
\hline unexpected order flow & 1.32 & 1.44 & 2.11 \\
\hline medium-sized order flow & 1.15 & 0.52 & 0.77 \\
\hline order flow & $2.63 *$ & 0.06 & $2.50 *$ \\
\hline medium-sized order flow & 0.27 & 0.60 & 0.76 \\
\hline order flow & 2.03 & 0.01 & $2.49 *$ \\
\hline unexpected order flow & $2.81 *$ & 1.40 & 2.13 \\
\hline \multirow[t]{3}{*}{$\underline{\text { Panel B }}$} & \multicolumn{3}{|c|}{ F-statistics } \\
\hline & \multicolumn{3}{|c|}{ maturity } \\
\hline & 2-year & 5-year & 10-year \\
\hline order flow & 1.32 & 0.07 & 1.38 \\
\hline unexpected order flow & $2.80 *$ & 1.51 & $3.73 * *$ \\
\hline medium-sized order flow & 0.28 & 0.70 & 0.84 \\
\hline unexpected order flow & 1.30 & 1.16 & $2.47 *$ \\
\hline medium-sized order flow & 0.99 & 0.91 & 0.96 \\
\hline order flow & 2.09 & 0.22 & $2.52 *$ \\
\hline medium-sized order flow & 0.26 & 0.91 & 0.77 \\
\hline order flow & 1.58 & 0.13 & $2.44 *$ \\
\hline unexpected order flow & $2.55^{*}$ & 1.24 & $2.72 *$ \\
\hline \multirow[t]{3}{*}{$\underline{\text { Panel C }}$} & \multicolumn{3}{|c|}{ F-statistics } \\
\hline & \multicolumn{3}{|c|}{ maturity } \\
\hline & 2-year & 5-year & 10-year \\
\hline order flow & $2.38^{*}$ & 0.45 & 1.38 \\
\hline unexpected order flow & $3.43^{* *}$ & 1.85 & 1.64 \\
\hline medium-sized order flow & 0.46 & 0.33 & $2.52 *$ \\
\hline unexpected order flow & 1.29 & 2.16 & 0.75 \\
\hline medium-sized order flow & 0.75 & 0.24 & 1.20 \\
\hline order flow & $4.21 * *$ & 0.25 & $3.59 * *$ \\
\hline medium-sized order flow & 0.21 & 1.15 & 1.27 \\
\hline order flow & $3.48 * *$ & 0.20 & $3.68 * *$ \\
\hline unexpected order flow & $2.56^{*}$ & 1.29 & 0.61 \\
\hline
\end{tabular}




\section{Table 9: Impact parameters on daily information shares' fluctuations of the 10-year future}

Results report regression results of trend variables, news and log-shares of microstructure variables on logarithmic transformations of the daily information shares of the ten-year future, compared to the two- and five-year future. Robust standard errors (Newey-West, 1987) are used. The intercept term, time-to-maturity and delivery days of futures and options, which are included in all regressions, are not reported for brevity. News variables represent the absolute values of the difference between the realized and expected value, each standardized by dividing by its standard deviation. The $10 \%(5 \%$, $1 \%)$ significance level is marked with a $*(* * / * * *)$.

\begin{tabular}{|c|c|c|c|c|c|c|}
\hline \multirow[b]{2}{*}{ variable } & \multicolumn{3}{|c|}{10 -year to 2 -year } & \multicolumn{3}{|c|}{ 10-year to 5-year } \\
\hline & $\begin{array}{c}\text { Hasbrouck } \\
\text { information } \\
\text { share }\end{array}$ & $\begin{array}{c}\text { Modified } \\
\text { information } \\
\text { share }\end{array}$ & $\begin{array}{c}\text { HMW } \\
\text { information } \\
\text { share }\end{array}$ & $\begin{array}{c}\text { Hasbrouck } \\
\text { information } \\
\text { share }\end{array}$ & $\begin{array}{c}\text { Modified } \\
\text { information } \\
\text { share }\end{array}$ & $\begin{array}{c}\text { HMW } \\
\text { information } \\
\text { share }\end{array}$ \\
\hline \multicolumn{7}{|l|}{$\underline{\text { trading-related }}$} \\
\hline spread & $1.120 * * *$ & $1.084 * * *$ & $1.427 * * *$ & $5.199 * *$ & $5.168 * *$ & $6.790 * *$ \\
\hline volume & $3.467 * * *$ & $3.434 * * *$ & $2.887 * * *$ & $2.940 * * *$ & $2.951 * * *$ & $2.205 * * *$ \\
\hline volatility & $-1.123 * *$ & $-1.041 * *$ & $-4.815^{* * *}$ & $-1.221 * * *$ & $-1.146 * * *$ & $-2.146 * * *$ \\
\hline \multicolumn{7}{|l|}{ macroeconomic news } \\
\hline \multicolumn{7}{|l|}{$\underline{\mathrm{US}}$} \\
\hline nonfarm payroll employment & $-0.389 * * *$ & $-0.389 * * *$ & $-0.384 * * *$ & $-0.275 * * *$ & $-0.266 * * *$ & $-0.271 * * *$ \\
\hline jobless claims & $0.168 * * *$ & $0.202 * * *$ & $0.201 * * *$ & 0.021 & 0.035 & 0.089 \\
\hline PPI & 0.018 & 0.021 & 0.017 & $-0.146^{*}$ & $-0.142 *$ & $-0.164 * *$ \\
\hline GDP & -0.013 & -0.018 & 0.015 & $-0.086 * *$ & $-0.079 *$ & $-0.163 * * *$ \\
\hline retail sales & $0.326 * * *$ & $0.339 * * *$ & $0.424 * * *$ & $0.395 * * *$ & $0.382 * * *$ & $0.411 * *$ \\
\hline CPI & 0.055 & 0.047 & 0.050 & 0.026 & 0.025 & -0.044 \\
\hline FOMC & $0.139 * *$ & $0.135 * *$ & 0.126 & -0.064 & -0.074 & 0.020 \\
\hline \multicolumn{7}{|l|}{$\underline{\text { Euro Area }}$} \\
\hline jobless claims & -0.035 & -0.041 & -0.060 & $0.079 *$ & $0.070 *$ & -0.015 \\
\hline PPI & 0.116 & 0.112 & 0.065 & -0.051 & -0.047 & -0.044 \\
\hline GDP & $-0.864 * * *$ & $-0.829 * * *$ & $-0.657 * *$ & -0.043 & -0.038 & 0.111 \\
\hline retail sales & -0.189 & -0.196 & -0.171 & $-0.225 * *$ & $-0.224 * *$ & $-0.315 * * *$ \\
\hline CPI & -0.076 & -0.075 & -0.066 & $-0.124 * *$ & $-0.124 * *$ & $-0.161 * * *$ \\
\hline ECB conferences & $-0.214 * *$ & $-0.240 * *$ & -0.145 & -0.037 & -0.031 & -0.054 \\
\hline \multicolumn{7}{|l|}{$\underline{\text { German }}$} \\
\hline jobless claims & $-0.166 * * *$ & $-0.167 * * *$ & $-0.192 * * *$ & $-0.136 * * *$ & $-0.134 * * *$ & $-0.195 * * *$ \\
\hline PPI & 0.071 & 0.064 & 0.085 & -0.035 & -0.037 & -0.066 \\
\hline GDP & $0.574 * * *$ & $0.551 * * *$ & 0.447 & -0.131 & -0.129 & $-0.230 * * *$ \\
\hline retail sales & -0.084 & -0.079 & -0.050 & 0.021 & 0.021 & 0.002 \\
\hline CPI & $-0.107 * * *$ & $-0.104 * * *$ & $-0.128 * *$ & $-0.190 * * *$ & $-0.180 * * *$ & $-0.205 * * *$ \\
\hline industrial production & $-0.179 * *$ & $-0.175 * *$ & $-0.190 * *$ & $-0.145^{*}$ & $-0.148 * *$ & $-0.253 * * *$ \\
\hline ifo business climate & $0.354 *$ & $0.339^{*}$ & $0.315^{*}$ & 0.142 & 0.134 & 0.049 \\
\hline \multicolumn{7}{|l|}{$\underline{\text { informed trading related }}$} \\
\hline \multicolumn{7}{|l|}{ order flow } \\
\hline all days & $0.171 * * *$ & $0.165^{* * *}$ & $0.184 * * *$ & 0.033 & 0.034 & 0.014 \\
\hline at announcement days & -0.020 & -0.013 & -0.035 & $0.180 * * *$ & $0.171 * * *$ & $0.192 * * *$ \\
\hline \multicolumn{7}{|l|}{ unexpected order flow } \\
\hline all days & $0.064 * * *$ & $0.064 * * *$ & 0.029 & $0.174 * * *$ & $0.172 * * *$ & $0.155 * * *$ \\
\hline at announcement days & $-0.113 * * *$ & $-0.110 * * *$ & $-0.078 * * *$ & $-0.179 * * *$ & $-0.179 * * *$ & $-0.137 * * *$ \\
\hline \multicolumn{7}{|l|}{ medium-sized order flow } \\
\hline all days & $-1.382 * * *$ & $-1.275 * * *$ & $-0.719 * *$ & $-1.196 * *$ & $-1.369 *$ & -0.305 \\
\hline at announcement days & $1.009 * * *$ & $0.967 * * *$ & $0.636 * * *$ & $1.655 * * *$ & $1.690 * * *$ & $1.085 * * *$ \\
\hline adjusted $\mathrm{R}^{2}$ & $7.2 \%$ & $7.2 \%$ & $6.1 \%$ & $3.0 \%$ & $2.7 \%$ & $5.3 \%$ \\
\hline
\end{tabular}


Table 10: Price discovery leadership

This table summarizes the results of testing whether one contract is the main contributor in the price discovery process compared to another contract. The corresponding dummy variables take value 1 if either a higher information share or a leading role, derived from lead-lag-regressions, is observable. The total numbers of dominant days and the corresponding means are reported. Additionally, the Zstatistics and p-value are reported, testing the null hypothesis of a mean larger than 0.5.

\begin{tabular}{|c|c|c|c|c|c|c|}
\hline & \multicolumn{2}{|c|}{ 2-year vs. 5-year } & \multicolumn{2}{|c|}{ 2-year vs. 10 -year } & \multicolumn{2}{|c|}{ 5-year vs. 10 -year } \\
\hline & $\mathrm{D}(2$-year, 5 -year $)$ & $\mathrm{D}(5$-year, 2-year) & $\mathrm{D}(2$-year, 10 -year $)$ & $\mathrm{D}(10$-year, 2-year) & $\mathrm{D}(5$-year, 10 -year $)$ & $\mathrm{D}(10$-year, 5-year) \\
\hline total & 232 & 437 & 233 & 511 & 227 & 477 \\
\hline mean & 0.300 & 0.565 & 0.301 & 0.661 & 0.294 & 0.617 \\
\hline z-stat & -12.117 & 3.662 & -12.024 & 9.454 & -12.588 & 6.692 \\
\hline (p-value) & $(1.000)$ & $(0.000)$ & $(1.000)$ & $(0.000)$ & $(1.000)$ & $(0.000)$ \\
\hline
\end{tabular}

